\title{
GEORGE KEITH BATCHELOR'S INTERACTION WITH CHINESE FLUID DYNAMICISTS AND INSPIRATIONAL INFLUENCE: A HISTORICAL PERSPECTIVE
}

\author{
by
}

JoHN Z. SHI*

\begin{abstract}
State Key Laboratory of Ocean Engineering, School of Naval Architecture, Ocean and Civil Engineering, Shanghai Jiao Tong University, 1954 Hua Shan Road, Shanghai 200030, China

G. K. Batchelor Laboratory, Department of Applied Mathematics and Theoretical Physics, University of Cambridge, Wilberforce Road, Cambridge CB3 OWA, UK Currently visiting: Emmanuel College Cambridge, St Andrew's Street, Cambridge CB2 $3 A P, U K$
\end{abstract}

George Keith Batchelor (1920-2000, FRS 1957) was a towering figure in the twentieth century international fluid mechanics community. Much has been written about him since his death. This article presents an account of Batchelor's early interactions and relationships with Chinese fluid dynamicists and his continuing inspirational influence on them, which have not yet been documented in English. The theory of homogeneous turbulence, to which Batchelor contributed greatly, has had both indirect and direct inspirational influence on generations of Chinese fluid dynamicists, as they have sought to make their own contributions. Batchelor made visits to China in 1980 and 1983. His first ice-breaking trip to China in April 1980 is of special importance to Sino-British fluid mechanics and to China, even though Batchelor did not speak about turbulence but instead about his more recent research interest, microhydrodynamics. Batchelor's philosophical view of applied mathematics (fluid mechanics) - that 'You have got to inject some physical thinking as well as mathematical thinking'-has had great inspirational influence on generations of fluid dynamicists in the UK, in China, and around the world. Batchelor's generosity of spirit and frugality of habit is warmly remembered by his students and Chinese friends. The author presents details of Batchelor's interaction with Chinese fluid dynamicists in the 1980s within the general context of the scientific relationship between China and the UK.

Keywords: George Keith Batchelor; Chinese fluid dynamicists; turbulence; interaction; inspirational influence; physical thinking; mathematical thinking

Owing to the length and number of citations in the paper, conventional Chicago referencing has not been employed in this article in the interests of clarity.

*zshi@sjtu.edu.cn 


\section{INTRODUCTION}

On the whole, Genius has privileges of its own; it selects an orbit for itself; and be this never so eccentric, if it is indeed a celestial orbit, we mere stargazers must at last compose ourselves; must cease to cavil at it, and begin to observe it, and calculate its laws. ${ }^{1}$

George Keith Batchelor (1920-2000, FRS 1957; figure 1) is truly an important planet (or star) in the international fluid mechanics heavens, a man whose history deserves to be recorded. The story of so distinguished a person as Batchelor could scarcely fail to be interesting, and much has been written about Batchelor and his work on fluid mechanics. ${ }^{2}$ Just after $^{2}$ the death of Batchelor, $\mathrm{Li}^{3}$ wrote an obituary for him in Chinese. There are also brief accounts of Batchelor's relationships with his contemporaries. ${ }^{4,5}$ If any general conclusions can be drawn from previous accounts,, Batchelor appears as 'a revered, if sometimes controversial, personality'. ${ }^{6}$

Batchelor was born and grew up in Melbourne, Victoria, Australia. His father was George Conybere Batchelor (1897-1985) and his mother was Ivy Constance Berneye (1899-1943). His family home was at 107 Eglinton Street, Moonee Ponds, Melbourne. He attended the local Essendon High School (1931-1934), before receiving prestigious scholarships to attend Melbourne High School (1935-1936) and the University of Melbourne (1937-1940), from which he graduated with a degree in mathematics and physics in $1940 .{ }^{7}$ Batchelor subsequently completed a theoretical thesis entitled 'Two-dimensional subsonic flow of a compressible fluid', which was presented for the degree of Master of Science, University of Melbourne, in February 1941. ${ }^{8}$ After World War II, he then studied turbulence under the tutelage of Geoffrey Ingram Taylor (FRS 1919) at Cambridge, UK from 1945 to January 1948. He completed his PhD thesis entitled 'The statistical theory of isotropic turbulence' in January 1948. Batchelor was elected a Fellow of the Royal Society of London in $1957 .{ }^{9}$

'Cambridge was my scientific Mecca', Batchelor wrote. ${ }^{10}$ In the autumn of 2012 and in 2019, the present author came as a senior visitor to the G. K. Batchelor Laboratory, in the

1 T. Carlyle, 'Jean Paul Friedrich Richter', Edinb. Rev. 91 (1827).

2 J. C. R. Hunt, 'Professor George Batchelor', The Independent, 17 April 2000, H. E. Huppert, 'George Keith Batchelor 8 March 1920-30 March 2000', J. Fluid Mech. 421, 1-14 (2000), T. J. Pedley, 'Marrying maths and mechanics in Cambridge', The Guardian, 12 April, 2000, J. Rallison, 'The don who understood turbulence', The Telegraph, 18 April, 2000, G. I. Barenblatt, 'George Keith Batchelor (1920-2000) and David George Crighton (1940-2000)', Notices AMS 48, 800-806 (2001), L. van Wijngaarden, 'G. K. Batchelor (1920-2000)', Eur. J. Mech. B Fluids 20, 3-5 (2001), H. K. Moffatt, 'George Batchelor. Cambridge scientists who set exacting standards in fluid mechanics', The Times, 12 April 2000, H. K. Moffatt, 'G. K. Batchelor and the homogenization of turbulence', Аnnu. Rev. Fluid Mech. 34, 19-35 (2002), H. K. Moffatt, 'George Keith Batchelor 8 March 1920—March 2000', Biogr. Mems Fell. R. Soc. Lond. 48, 25-41 (2002), at p. 34, H. K. Moffatt, 'George Batchelor: a personal tribute, ten years on', J. Fluid Mech. 663, 2-7 (2010), H. K. Moffatt, 'G. Batchelor, 'The post-war renaissance of research in turbulence', in A voyage through turbulence (eds P. A. Davidson, Y. Kaneda, K. Moffatt, and K. R. Sreenivasan), pp. 276-304 (Cambridge University Press, 2011), J. H. Arakeri, 'G. K. Batchelor (1920-2000)', Reson. J. Sci. Educ. 15, 297-299 (2010).

3 J. C. Li, 'In memorial of G. K. Batchelor' (in Chinese), Adv. Mech. 30, 471 (2000).

4 H. K. Moffatt, op. cit. (note 2).

5 G. Farmelo, The strangest man. The hidden life of Paul Dirac, mystic of the atom, pp. 365, 367, 374, 387 (Basic Books, New York, 2009), M. Eckert, 'Turbulence before Marseille 1961', J. Turbulence 13, 1-25 (2012), at pp. 16 and 17, R. Narasimha, A. Roshko and M. Gharib, 'Hans W. Liepmann, 1914-2009', Annu. Rev. Fluid Mech. 45, 1-17 (2013), at p. 11, paragraph 3, lines 3-6; at pp. 13 and 14, K. R. Sreenivasan, 'Chandrasekar's fluid dynamics', Annu. Rev. Fluid Mech. 51, 1-24 (2019), at pp. 6, 7, 9 and 10.

6 H. K. Moffatt, op. cit. (note 2).

7 Keith Moffatt's preface to the Batchelor Archive, Wren Library, Trinity College, Cambridge (hereafter 'Batchelor Archive').

8 G. K. Batchelor, copy of MSc thesis, Batchelor Archive.

9 G. K. Batchelor, CV copy in the Batchelor Archive.

10 G. K. Batchelor, 'Research as a life style', Appl. Mech. Rev. 50, R11-R20 (1997), at R12, last paragraph, line 4. 


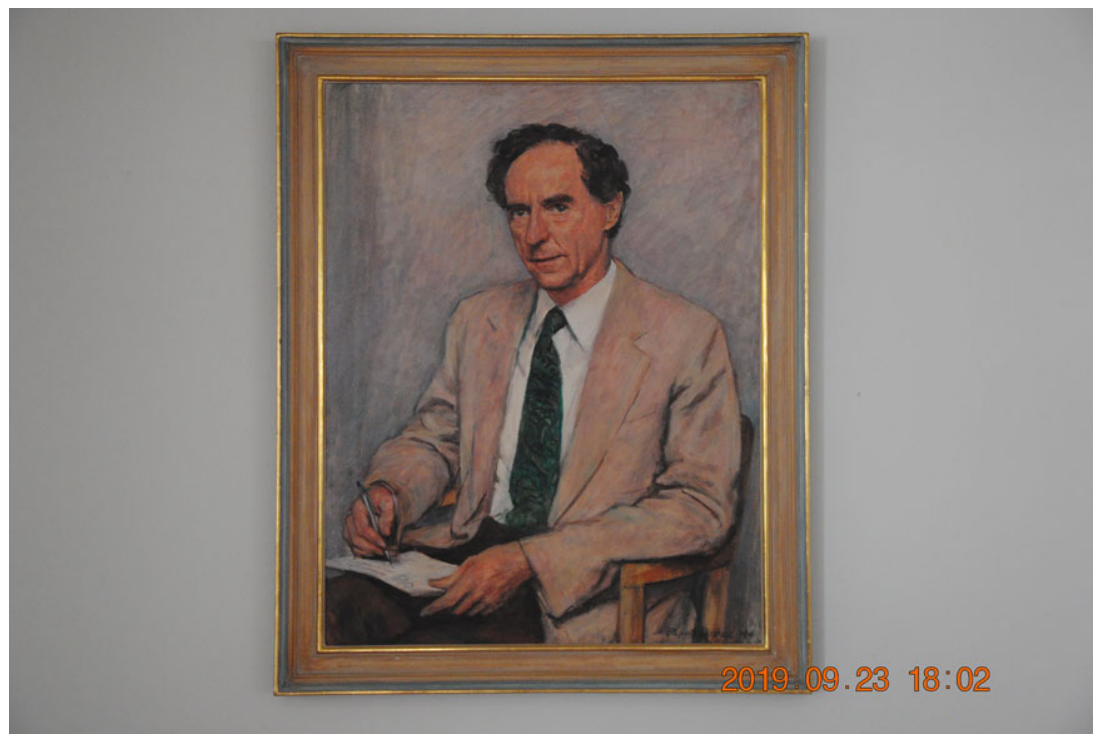

Figure 1. An enigmatic portrait of George Keith Batchelor wearing his usual fawn colour jacket painted by Rupert Norman Shephard (1909-1992) in 1984 hangs in the Common Room of Pavilion G of the Department of Applied Mathematics and Theoretical Physics (DAMPT), University of Cambridge. Photo Credit: John Z. Shi. (Online version in colour.)

Department of Applied Mathematics and Theoretical Physics (DAMPT), at the University of Cambridge, UK. The present author learned about homogeneous, isotropic turbulence by reading Batchelor's 22 single-authored and 10 or so co-authored papers on the subject, plus his book on The theory of homogeneous turbulence. ${ }^{11}$ Ever since, the thought of writing about Batchelor's interaction with Chinese fluid dynamicists has had a growing appeal even though I never met this remarkable man. This year is the centenary of Batchelor's birth, and also marks the fortieth anniversary of Batchelor's ice-breaking trip to six different institutes and universities in China in April 1980, which opened a significant chapter in the history of Sino-British fluid mechanics.

Given that a general reader of this article may not be familiar with fluid dynamics, even to the extent of knowing what turbulence or the Reynolds number is, a brief introduction is presented here. There are two types of fluid flow conditions: laminar flow and turbulent flow. Laminar flow is known as streamline flow; it is organized flow free of turbulence. Turbulent flow is characterized by a fluid flowing in a random way. The Reynolds number is dimensionless, being a measure of the ratio of inertial forces to viscous forces, quantifying the relative importance of these two types of force for flow conditions, i.e. it indicates whether or not flow is laminar or turbulent.

The present author's own research on turbulence has been almost exclusively influenced by Batchelor's book on The theory of homogeneous turbulence. ${ }^{11}$ However, the importance of 
the great Russian contribution to turbulence as summarized in Monin and Yaglom should not be neglected. ${ }^{12,13}$

This article proceeds with a short history of Chinese physicists' early interactions with British physicists at Cambridge and then gives a historical account of Batchelor's early interaction with the Chinese fluid mechanics community and with individual Chinese fluid dynamicists. Given the research interests of the present author, the paper also selectively introduces Batchelor's work on turbulence in relation to his strong, inspirational influence on generations of Chinese fluid dynamicists. These are mainly from mainland China. However, a couple of American Chinese fluid dynamicists, who were born in China, and even died in China, are also introduced. It is not so easy to organize the overall structure of the contents but the narrative is presented in roughly chronological order.

Within the general context of historiography, Agar looks at the China-UK scientific relationship before and during the 1970s. ${ }^{14}$ The present paper suggests that Batchelor's work with China in the 1980s can be placed in a wider context, particularly in respect of renewing the China-UK scientific relationship in the 1970s as delineated by Agar. ${ }^{14}$

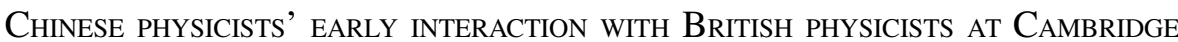

To set the stage, let us take a short journey back over the early development of Chinese fluid mechanics. In a sense, Chinese fluid mechanics was rooted in Chinese physics, even though early interaction with British physicists centred at Cambridge had begun in the 1930s and especially the 1940s during World War II.

Paul Dirac (1902-1984, FRS 1930), who won the Nobel Prize in Physics in 1933 at the age of 31, was Lucasian Professor of Mathematics at the Cavendish Laboratory, and also an early member of DAMTP, University of Cambridge, when it was founded in 1960. Peiyuan Chou (1902-1993), a theoretical physicist who obtained his PhD from the California Institute of Technology in 1928, worked at the National Tsinghua University and Peking University. At the invitation of Chou, Dirac visited the National Tsinghua University in July 1935. Dirac's visit was successful and had an important influence on the Chinese physics community. Dirac was the first member of DAMTP to visit China. This marked the start of a long series of interactions between Chinese and British physicists which persists today.

Chou did not begin to study turbulence with his students Chia-Chiao Lin (1916-2013), Ning Hu (1916-1997) and Yung-Huai Kuo (1909-1968) until 1938, when he was at the age of 36. In the 1930s and 1940s, Chou, at the National Tsinghua University in Peking, had both indirect and direct relationships with Taylor of the University of Cambridge. JwuShi Wang (1911-1983) might be thought of as the first Chinese student sent by Chou to study turbulence at Cambridge. However, Wang had earlier studied theoretical physics under the supervision of Ralph Howard Fowler (1889-1944, FRS 1925) in September 1935, and he also attended fluid dynamics lectures by Sydney Goldstein (1903-1989, FRS

12 A. S. Monin and A. M. Yaglom, Statistical fluid mechanics: mechanics of turbulence, vol. 1 (trans. from the Russian edition (Moscow, 1965), as revised by the authors), (ed. John L. Lumley), xii+770 pp. (MIT Press, Cambridge, MA, 1971).

13 A. S. Monin and A. M. Yaglom, Statistical fluid mechanics: mechanics of turbulence. vol. 2 (trans. from the Russian edition (Moscow, 1967), as revised by the authors), (ed. John L. Lumley), 896 pp. (MIT Press, Cambridge, MA, 1975).

14 J. Agar, 'It's springtime for science': renewing China-UK scientific relations in the 1970s', Notes Rec. R. Soc. Lond. 67, 7-24 (2013). 
1937) at Cambridge. Other Chinese students also planned to study mechanics with Taylor at Cambridge, supported by the Boxer Rebellion Indemnity Scholarship in 1939, including Yung-Huai Kuo (1909-1968), Wei-Zang Chien (1912-2010) and Chia-Chiao Lin (19162013). However, their plan to study with Taylor was overtaken by the outbreak of World War II. They went to Canada instead where they did their research at the University of Toronto under the supervision of John Lighton Synge (1897-1995, FRS 1943). Significant work was done by Chia-Chiao Lin in conjunction with Synge; Synge and Lin ${ }^{15}$ developed a statistical theory of homogeneous isotropic turbulence by regarding turbulent fluctuations as being due to Hill's ${ }^{16}$ vortices moving about chaotically.

In his first paper on turbulence, $\mathrm{Chou}^{17}$ added the following note in the proofs of his paper:

Prof. G. I. Taylor, to whom the author must express his gratitude, has pointed out in a private communication that the assumption (6.1) $p_{2}^{\prime}=p_{3}^{\prime}=0$ cannot hold physically. The original reason for assuming this was purely for simplifying mathematical manipulation without, however, introducing contradictions into the set of equations from (5.1) to (5.19), while physically this is certainly not true. In fact the assumption (6.1) is not necessary ....

( $p$ is the pressure term). The significance of this note is twofold: on the one hand, it provides some published evidence that Chou interacted with Taylor; on the other, it indicates that Chou was grateful for Taylor's constructive comment and explicitly acknowledged it.

$\mathrm{Chou}^{18}$ presented a keynote talk entitled 'On the theory of turbulence for incompressible fluid' at the Third Chinese Conference on Turbulence and Instability of Fluid, 8 October 1991, at Tianjin University. Chou recalled that he wrote to Taylor about his work on turbulence $^{17}$ in the 1940 s, but did not receive any reply. However, Taylor kindly shipped Chou more than 200 copies of Philosophical Transactions, which were given to the National Tsinghua University after World War II. This was the first stage of Chinese work on turbulence. ${ }^{18}$

As one example of indirect Sino-British fluid dynamicists' interaction, employing the methods of Chou, ${ }^{17} \mathrm{Hu}^{19}$ presented the earliest theoretical investigation of turbulent motion in the wake, using the methods of the statistical theory of turbulence. It was both favourably and critically reviewed by Alan A. Townsend (FRS 1960). ${ }^{20,21}$ The theoretical investigation by Hu, although it predicts velocity and temperature distributions with reasonable accuracy, does not explain the observed distribution of turbulent intensities across the wake, ${ }^{20}$ and the assumption of a constant energy-diffusion coefficient by $\mathrm{Hu}^{19}$ is almost certainly incorrect. ${ }^{21}$ Another example of an indirect interaction between Sino-British fluid dynamicists that of Feng-Kan Chuang (1925-2010). He became a very important figure in Chinese aeronautical engineering after his return to mainland China, when he completed his $\mathrm{PhD}$ thesis entitled 'On the statistical theory

15 J. L. Synge and C. C. Lin, 'On a statistical model of isotropic turbulence', Trans. R. Soc. Can. 37, 1-35 (1943).

16 M. J. M. Hill, 'On a spherical vortex', Phil. Trans. R. Soc. Lond. A 185, 213-245 (1894).

17 P. Y. Chou, 'On an extension of Reynolds' method of finding apparent stress and the nature of turbulence', Chin. J. Phys. 4, $1-33$ (1940).

18 P. Y. Chou, 'On the theory of turbulence for incompressible flow' (in Chinese), Mech. Engng 24, 1-9 (2002).

19 N. Hu, 'Velocity and temperature distributions in turbulent wakes behind a row of equally spaced parallel rods and behind a square grid', Chin. J. Phys. 5, 30-48 (1944).

20 A. A. Townsend, 'Measurements in the turbulent wake of a cylinder', Proc. R. Soc. Lond. A 190, 551-561 (1947).

21 A. A. Townsend, 'Momentum and energy diffusion in the turbulent wake of a cylinder', Proc. R. Soc. Lond. A 197, 124-140 (1949). 
of turbulence, $^{\text {,2 }}$ under the guidance of Hans Wolfgang Liepmann (1914-2009) at the California Institute of Technology, Pasadena, in 1950. He wrote in his thesis abstract that 'The present work starts with a study of isotropic turbulence which was introduced by G. I. Taylor in 1935.' Chuang critically examined the different notions of averages and instead introduced the notion of stochastic average. Correspondence was made between the von Kármán-Howarth ${ }^{23}$ equation and the spectrum equation of turbulence. Chuang obtained a relation between Heisenberg's ${ }^{24}$ and Taylor's ${ }^{25}$ spectrum. Chuang improved linearized vorticity transport theory and took into account non-linear effects in turbulence.

The work of $\mathrm{Chou}^{26}$ is used to eliminate the pressure term from the Navier-Stokes equation using the incompressibility condition and this has been the basis of all statistical theories of turbulence for many decades, although the work of Chou is never mentioned. Everyone just starts from the solenoidal Navier-Stokes equation without mentioning Chou's pioneering role. Batchelor discussed a different method in his book on homogeneous turbulence. ${ }^{11}$ Chou's work was neglected due to World War II. Chou's work was recognized by some as having suffered from its timing relative to the war. ${ }^{27}$ However, $\mathrm{Chou}^{26}$ is highly referenced in McComb. ${ }^{28}$

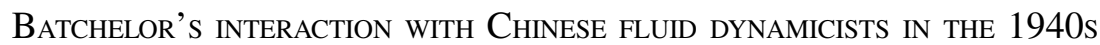

Carl H. Gibson, who chaired talks by Batchelor when he visited the University of California at San Diego in the 1980s, regarded G. I. Taylor as his hero of fluid mechanics. Gibson noted the talent of Batchelor, remarking that

Batchelor has a genius for not only having good ideas and communicating them very well. $\mathrm{He}$ also has the excellent talent in being able to recognize the good ideas of others and examples of who had good communications from others. The first talent is best illustrated by one of his first papers, written when he was a student at Trinity College, Cambridge, called Kolmogorov's theory of local isotropic turbulence presented in 1946 in the Proceedings of the Cambridge Philosophical Society. ${ }^{29}$ The second talent is illustrated by the fact that he is responsible for the existence of the very great success of the Journal of Fluid Mechanics. He is also very good at recognizing good people. ${ }^{30}$

His talents are also illustrated by his contributions to a number of learned societies, like the International Union of Theoretical and Applied Mechanics (IUTAM), the Polish annual fluid dynamics meeting, the European Mechanics Society (EUROMECH), etc.

22 F. K. Chuang, 'On the statistical theory of turbulence', PhD thesis, California Institute of Technology, Pasadena, CA (1950)

23 T. de Kármán and L. Howarth, 'On the statistical theory of isotropic turbulence', Proc. R. Soc. Lond. A 164, 192-215 (1938).

4 W. Heisenberg, 'On the theory of statistical and isotropic turbulence', Proc. R. Soc. Lond. A 195, 402-406 (1948).

5 G. I. Taylor, 'The spectrum of turbulence', Proc. R. Soc. Lond. A 164, 476-490 (1938).

26 P. Y. Chou, 'On velocity correlations and the solutions of the equations of turbulent fluctuation', Q. Appl. Math. 3, 38-54 (1945).

27 W. David McComb, personal communication, 16 June 2019.

28 W. D. McComb, The physics of fluid turbulence (Oxford University Press, 1990).

29 G. K. Batchelor, 'Kolmogoroff's theory of locally isotropic turbulence', Math. Proc. Camb. Phil. Soc. 43, 533-559 (1947)

30 Tape available in the Batchelor Archive. 
Batchelor's talent in being able to recognize and acknowledge the good ideas of others is illustrated by the fact that Kolmogorov's work ${ }^{31,32}$ was introduced to the West by Batchelor. ${ }^{29}$ In turn it is believed that Batchelor's interpretation of Kolmogorov's work also had a great influence on the Russian scientific community. ${ }^{33}$ The Russian research was known to the West. It is interesting that in his masterly interpretation of the ideas of Kolmogorov, ${ }^{31,32}$ Batchelor $^{29}$ acknowledged a contribution by the Chinese scholar, Professor P. Y. Chou (Peiyuan Chou).

\section{BATCHELOR's INSPIRATIONAL INFLUENCE ON ChINESE FLUID DYNAMiCISTS IN THE 1950s}

The concept of homogeneous, isotropic turbulence was conceptually coined and proposed by William Thomson (FRS 1851; later Lord Kelvin) ${ }^{34}$ and developed further by Taylor, ${ }^{35}$ de Kármán and Howarth (FRS 1950), ${ }^{23}$ Batchelor $^{11}$ and others. ${ }^{36,37}$

In mainland China, early studies of homogeneous, isotropic turbulence were first inspired by Synge and Lin. ${ }^{15}$ In a sense, it was Synge and Lin who introduced homogeneous, isotropic turbulence to Chinese fluid mechanics and the turbulence community in the 1950s. It was also Synge and $\operatorname{Lin}^{15}$ who introduced Hill's ${ }^{16}$ idea of a so-called 'spherical vortex' to Chou and his student, Shu-Tang Cai (1928-2008).

Acta Mechanica Sinica (now the Chinese Journal of Theoretical and Applied Mechanics) was founded at the Institute of Mechanics, Chinese Academy of Sciences (Academia Sinica), in 1957. In the 1950s, Chou's Chinese school of turbulence had been interested in homogeneous, isotropic turbulence, including the vorticity structure of homogeneous, isotropic turbulence in its final period of decay. ${ }^{38}$ Their results were compared with those of Batchelor and Townsend. ${ }^{39,40}$ The first article in the first issue of Acta Mechanica Sinica (Chinese version) was on homogeneous, isotropic turbulence by Chou and Tsai. ${ }^{38}$ In his later review article, ${ }^{41}$ Chou cited many of Batchelor's papers on this topic.

Chia-Shun Yih (1918-1997) was born in Guizhou, China, but lived in the USA. However, he regarded himself as being as much a Chinese citizen as an American. Yih wrote to YuanCheng Fung that 'I re-examine the aim of my Life, I wish to contribute my Life to the Chinese

31 A. N. Kolmogorov, 'The local structure of turbulence in incompressible viscous fluid for very large Reynolds numbers', Dokl. Akad. Nauk SSSR XXX, 299-303 (1941). (Reprinted in Proc. R. Soc. Lond. A 434, 9-13 (1991).)

32 A. N. Kolmogorov, 'Dissipation of energy in the locally isotropic turbulence'. Dokl. Akad. Nauk SSSR XXXII, 19-21 (1941). (Reprinted in Proc. R. Soc. Lond. A 434, 15-17 (1991).)

33 Stuart Dalziel, personal communication, 7 June 2019.

34 W. Thomson, 'On the propagation of laminar motion through a turbulently moving inviscid liquid', Phil. Mag. 24, 342-353 (1887).

35 G. I. Taylor, 'Statistical theory of turbulence', I, Proc. R. Soc. Lond. A 151, 421-444 (1935), G. I. Taylor, 'Statistical theory of turbulence', II, Proc. R. Soc. Lond. A 151, 444-454 (1935), G. I. Taylor, 'Statistical theory of turbulence', III, Proc. R. Soc. Lond. A 151, 455-464 (1935), G. I. Taylor, 'Statistical theory of turbulence', IV, Proc. R. Soc. Lond. A 151, 465-478 (1935), G. I. Taylor, 'Statistical theory of turbulence', V, Proc. R. Soc. Lond. A 156, 307-317 (1936).

36 W. K. George, 'The decay of homogeneous isotropic turbulence', Phys. Fluids A 4, 1492-1509 (1992).

37 W. D. McComb, Homogeneous, isotropic turbulence (Oxford University Press, 2014).

38 P. Y. Chou and S. T. Tsai, 'The vorticity structure of homogeneous isotropic turbulence in its final period of decay' (in Chinese with an English abstract), Acta Mech. Sin. 1, 3-14 (1957).

39 G. K. Batchelor and A. A. Townsend, 'Decay of isotropic turbulence in the initial period', Proc. R. Soc. Lond. A 193, 539558 (1948).

40 G. K. Batchelor and A. A. Townsend, 'Decay of isotropic turbulence in the final period', Proc. R. Soc. Lond. A 194, 527543 (1948), p. 538, figure 1; p. 540, figure 3.

41 Chou, P. Y., 'Modern developments in the theory of turbulence' (in Chinese with an English abstract), Chin. J. Phys. 13, 220-244 (1957). 


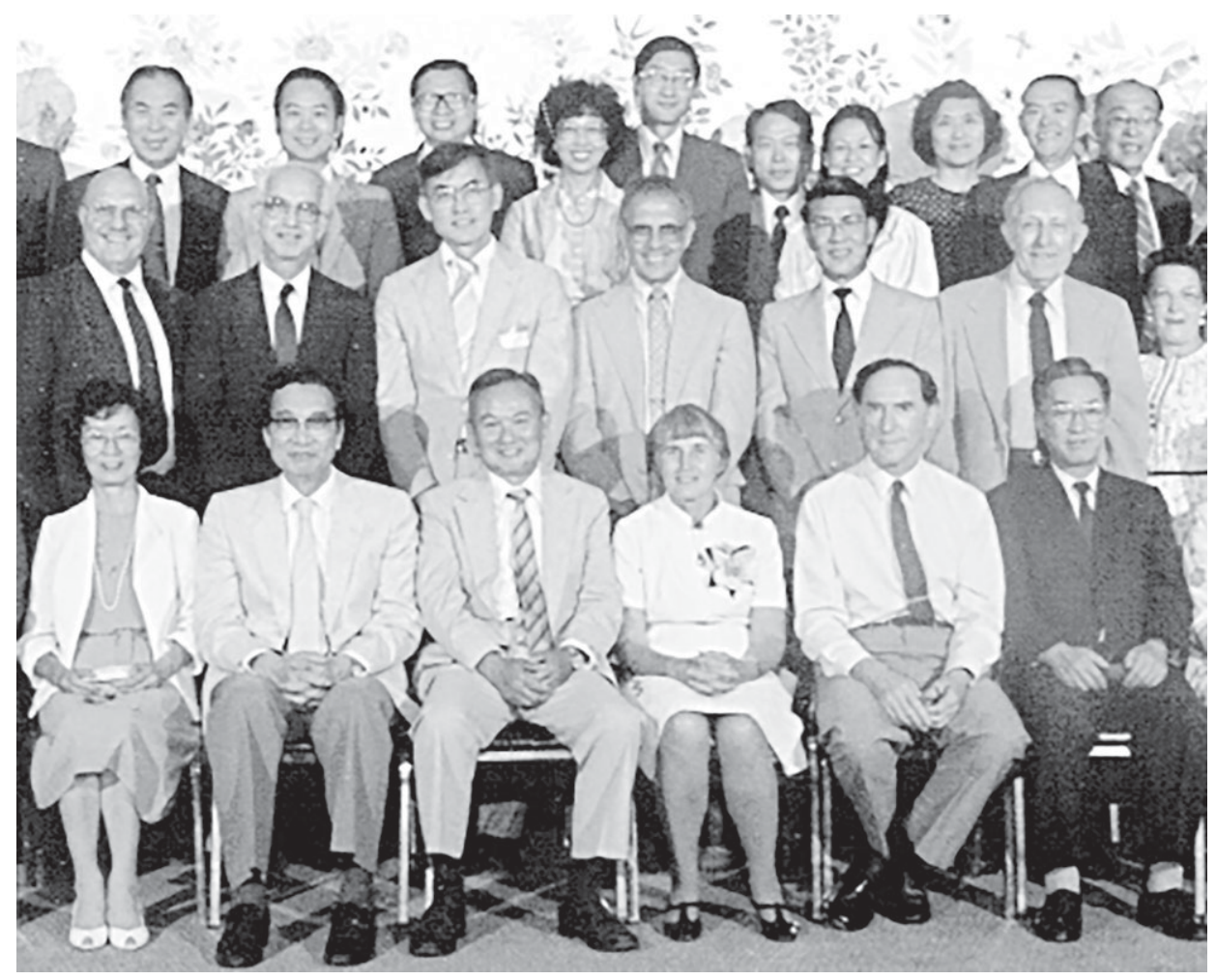

Figure 2. Photo of Chia-Shun Yih Symposium participants (1985), Ann Arbor, MI, USA. Chia-Shun Yih (first row, third from the left); Batchelor (first row, second from the right). Reproduced with permission from World Scientific Publishing Company (Copyright (c) 1991).

farmers. ${ }^{42}$ Yih visited DAMTP, Cambridge, from 1959 to 1960 , where he was kindly hosted by Batchelor.

A symposium in honour of Chia-Shun Yih was held in Ann Arbor, Michigan, in 1985. Batchelor attended this symposium (figure 2). As the outcome of that symposium two volumes of Selected Papers of Chia-Shun Yih were published by the World Scientific Publishers ${ }^{43}$. One of the prefaces, cited below, is an extract of Batchelor's reminiscence of Yih:

Chia-Shun Yih was the first Chinese fluid dynamicist I met, and naturally I assumed there were many others like him. I have not yet found one! Of all my friends, in any country, he is the most mercurial, the most emotional, and the most generous-spirited. It is unusual to find these qualities in a person with scientific interests, but in Chia-Shun they are combined happily. Given another life-time, one feels he might prefer to be a painter or a poet; but in his present incarnation he is outstanding as an applied mathematician, quick in perception, skilled in execution, and always on the look-out for a nice result which has both elegance

42 Y.-C. Fung, 'In memoriam fluid dynamicist Yih Chia-Shun' (in Chinese), Adv. Mech. 27, 433-435 (1997).

43 Lin, S. P. and Lai, W. M. (eds) 1991 Selected Papers by Chia-Shun Yih (in 2 Volumes), Advanced Series on Fluid Mechanics, World Scientific, 1064 pp. 
and meat.

I first met Chia-Shun in the 1950's. We are near-contemporaries, and we both had the good fortune to 'grow up' in research during those exciting early post-war years when there seemed to be so much useful basic research in fluid mechanics to be done. Our areas of specialization were not the same, but we had a few common interests, for example in free convection and hydrodynamic stability. He made some short visits to Cambridge, and fell in love with the beautiful old College buildings, the academic atmosphere, and the old-world values, things which he greatly missed in U.S.A. The idea of spending a whole academic year at Cambridge arose naturally between us, and a subsequent successful application to NSF for a visiting fellowship enabled him to live in Cambridge with his family during 1959-60. He was very interested in stratified fluid flow at the time, and this gave him common ground with a number of his Cambridge friends, especially Brooke Benjamin [FRS 1966], Alfred Binnie [FRS 1960], and Geoffrey Taylor. He was a marvelous visitor, he enjoyed everything, even the weather, and was especially appreciative of opportunities to observe the Cambridge scene, to learn a little of its history, and to take part in the ceremonies of daily College life. He referred later to this as being the happiest year of his life. Speaking as one of the residents, I can testify that we felt the gain was entirely on our side. His capacity for human warmth and affection and his enthusiasm for research in fluid mechanics win him friends everywhere. May they continue to do so. ${ }^{44}$

George Batchelor August 1990

An anecdote about Yih and Batchelor, in Poland, was reported, when Wladyslaw (Wladek) Fiszdon (1912-2004) organized one of his biennial symposia on 'Advanced Problems and Methods in Fluid Mechanics’ in Olsztyn, Poland, held 5-10 September 1977:

This was in the time 1960-1989, when scientists from Eastern Europe were not allowed to travel to Western Europe, but they could go to countries in Eastern Europe. I attended three or four times. The conditions were mostly rather primitive with respect to food and lodging. Batchelor was always there, as a friend of Poland, and at one of these occasions he had persuaded Chia-Shun Yih to come to Poland to attend such a symposium. But after a few days of primitive life, Chia-Shun Yih decided that he had experienced such conditions enough in China and that he wanted no more of it and he left. George Batchelor was angry with him because of this and said "If the people here can live all the time under these conditions, why can you not do it for one week?"45

James O. Wilkes, Professor Emeritus of Chemical Engineering, University of Michigan, reminisced:

Yes I did know Chia-Shun Yih fairly well ("Gus" as he was often called, although he was always 'Chia-Shun' to me and my wife) both at the University of Michigan (where I was on the ChE faculty from 1960-2000) and when he was on sabbatical leave at Cambridge in 1959. He and his wife Shirley lived about two miles from us in Ann Arbor. Chia-Shun was a delightful conversationalist, and was unfailingly cheerful and enthusiastic about everything he did. ${ }^{46}$

44 George Batchelor, file dated 1990, Batchelor Archive.

45 Leen van Wijngaarden, personal communication, 17 June 2019.

46 J. Wilkes, personal communication, 17 November 2019. 
In Batchelor's famous monograph The theory of homogeneous turbulence ${ }^{11}$ the works on turbulence of several Chinese physicists and fluid dynamicists were included, e.g. Tsung-Dao Lee, an American Chinese Nobel Prize laureate in Physics, and Chia-Chiao Lin, an American Chinese applied mathematician. In addition, Batchelor ${ }^{11}$ cited $\mathrm{Chou}^{26,47}$ and Djang, ${ }^{48}$ although he did not directly refer to their work in the text of the monograph. But it was notable that in his monograph Batchelor did not include the very important result on third moments structure by Kolmogorov, which had no arbitrary constant, although he had written about these famous papers published in 1947. He explained this omission in 1991 by noting that by 1953 there were not any convincing data to confirm the theory.

\section{BATCHELOR'S INSPIRATIONAL INFLUENCE ON CHINESE TURBULENCE RESEARCHERS IN THE 1960s}

Following de Kármán and Howarth, ${ }^{23}$ the final-period decay law of turbulent energy, i.e. the self-preserving solution, was obtained. ${ }^{49}$ Wind-tunnel measurements were made by Batchelor and Townsend ${ }^{40}$ at a low value of the mesh Reynolds number in order to investigate the final period of the decay of homogeneous, isotropic turbulence. As shown in Batchelor and Townsend, ${ }^{40}$ the above theoretical decay law for homogeneous, isotropic turbulence was generally confirmed by the few data points for $x_{1} / M>600$, where $x_{1}$ is the distance from the turbulence-generating grid and $M$ is the mesh size of the grid.

Hao Sheng Tan (1916-2005) obtained his PhD from Cornell University in 1949. He returned to China from the USA in 1965 and became one of the key figures in the Chinese mechanics community. One of Tan's major contributions was his work on final-stage decay of grid-produced turbulence ${ }^{50}$ when he worked for Therm in Ithaca, New York. Based on a kinetic model for the turbulence field, an inverse-square law was obtained for the energy of grid-produced turbulence in the final stage by Tan and Ling. ${ }^{50}$ By replotting the data of Batchelor and Townsend ${ }^{40}$ in a log-log graph, Tan and Ling ${ }^{50}$ reconfirmed the above decay law.

A discrepancy between Batchelor and Townsend ${ }^{40}$ and Tan and Ling $^{50}$ is reviewed in Hinze:

As pointed out earlier more than once, the difference between grid-generated turbulence in a uniform main flow and homogeneous, isotropic turbulence is that the first is axisymmetric, and inhomogeneous in the axial, main flow direction, though the degree of axial inhomogeneity has been assumed sufficiently small to justify the neglect of its effect. However, it might well be that this assumption is not correct, so that the decay law observed by Tan and Ling might be due to the actual axial inhomogeneity of the turbulence. ${ }^{51}$

47 P. Y. Chou, 'On velocity correlations and the equations of turbulent vorticity fluctuation', Sci. Rep. Nat. Tsing Hua Univ. 5 , 52-70 (1948).

48 G. F. Djang, 'A kinetic theory of turbulence', Chin. J. Phys. 7. 176-191 (1948).

49 G. K. Batchelor, 'Energy decay and self-preserving correlation functions in isotropic turbulence', Q. Appl. Math. VI, 97116 (1948).

50 H. S. Tan and S. C. Ling, 'Final stage decay of grid-produced turbulence', Phys. Fluids 6, 1693-1699 (1963), p. 1695, equation (8).

51 J. O. Hinze, Turbulence, 2nd edn, p. 276, 2nd paragraph (McGraw-Hill, New York, 1975). 


\section{BATCheloR's ICE-BREAKING TRIP TO ChINA IN APRIL 1980}

That friends should come to one from afar, is this not after all delightful? ${ }^{52}$

Batchelor did enjoy his interactions with scientists in other countries. In 1967 Chris Garrett (FRS 1993), Peter Rhines and Peter Schmitz drove to a fluid dynamics symposium in Poland at which Batchelor was a star, particularly as his book An introduction to fluid dynamics ${ }^{53}$ had just been published. ${ }^{54}$ However, Batchelor did not visit China until 1980.

The counterpart in mainland China of the Royal Society of London is the Chinese Academy of Sciences (Academia Sinica). Why did Batchelor decide to visit China and develop scientific collaborations with Chinese fluid dynamicists? First, the senior bilateral intergovernmental Science and Technology Agreement, which was the first treaty between the Chinese and British governments since 1949, was signed at Lancaster House, London, on 15 November 1978 by the British Foreign Secretary, David Owen, and by Chinese vice-premier Wang Chen. ${ }^{14}$ The timing of Batchelor's visit to China in 1980 seemed to be due to this treaty, i.e. the visit was a part of the general reconnection between the UK and China via science following 1978. Second, as discussed earlier, Batchelor had a talent for recognizing good ideas and for communication. Third, Batchelor was fully aware of contemporary Chinese work, e.g. that of Chou. Batchelor had an international vision. In his own words without censorship, Batchelor said that he was 'sympathetic and pitiful [unfortunate] for the 'Orient', (a historical term for the East). ${ }^{55}$

Through the relationship between the Royal Society and the Chinese Academy of Sciences, Batchelor and his wife, Wilma, made their joint ice-breaking visit to China during the period of 4-23 April 1980. During the course of their visit to China, after entering China from Hong Kong, they stayed in Peking, Xi'an, Shanghai and, on two overnight occasions, in Guangzhou. ${ }^{56}$ Batchelor visited the following institutes and universities: Institute of Mechanics, Chinese Academy of Sciences, Peking; Department of Mechanics, Peking University, Peking; Department of Engineering Mechanics and Hydraulic Engineering, Tsinghua University, Peking; Institute of Atmospheric Physics, Chinese Academy of Sciences, Peking; Departments of Mathematics, Mechanics, and Machine Power Engineering, Xi'an Jiao Tong University, Xi' an; Department of Mathematics, Fudan University, Shanghai; Departments of Applied Mathematics and Engineering Mechanics, Shanghai Jiao Tong University, Shanghai. During his visit, Batchelor delivered four lectures: ${ }^{57}$ (1) The rheological properties of colloidal dispersions; (2) Brownian diffusion of particles with hydrodynamic interaction; (3) Mass transfer from particles suspended in turbulent fluid; (4) The life and work of G. I. Taylor.

Batchelor's acceptance of the invitation to visit China was indeed a triumph both for the Chinese fluid mechanics community and for China. After ten years of the Cultural Revolution, scientific links between the People's Republic of China and the UK were rebuilt, a triumph for the Chinese fluid mechanics community scientifically, and for China

52 A. Waley, The Analects, p. 75, lines 2-4 (Everyman's Library, New York, 2000).

53 G. K. Batchelor, An introduction to fluid dynamics (Cambridge University Press, 1967).

54 Chris Garrett, personal communication, 1 June 2019.

55 Fu Chia, personal communication, 25 June 2019.

56 Report on a visit to China as an accompanying wife under the exchange agreement between the Royal Society and the Chinese Academy of Sciences, 4-23 April 1980, Batchelor Archive.

57 Report on a visit to China under the exchange agreement between the Royal Society and the Chinese Academy of Sciences, 4-23 April 1980, dated May 1980, Batchelor Archive. 


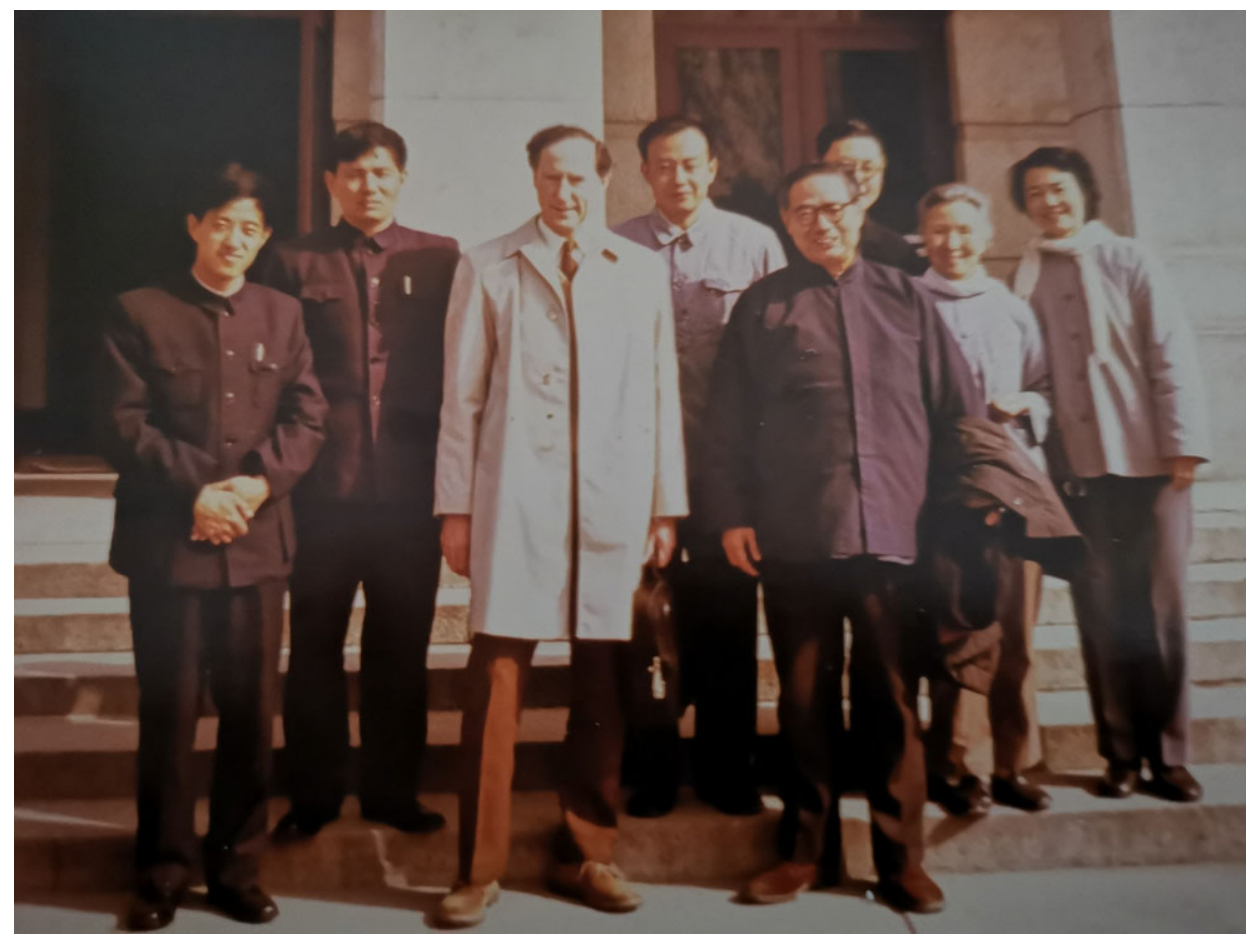

Figure 3. Batchelor on his first 'ice-breaking' trip to the Institute of Mechanics, Chinese Academy of Sciences, Peking, China, in April 1980. From left to right are Yuansheng Ma, Ching Shen (1935-2011), George Batchelor (1920-2000), Fu Chia, Haosheng Tan (1916-2005), Dexiang Guan, Pei Li (1917-2017), the widow of Yung-Huai Kuo (1909-1968), and Tan's wife Tuanzi Deng (1926-2013). (Online version in colour.)

politically. Given that more materials are available regarding his visit to the Institute of Mechanics, Chinese Academy of Sciences, Peking, than for other institutions I shall focus mainly on his visit to this institute and only briefly describe his visit to other institutes and universities. The Institute of Mechanics, Chinese Academy of Sciences, originated from the Research Laboratory of Mechanics headed by Weichang Qian (1912-2010) in 1953 and was fully established in 1956 by Hsue-Shen Tsien (1911-2009), after his return to China from Theodore von Kármán's group at Caltech. The Institute of Mechanics was the first Chinese research institute in mechanics in mainland China. Batchelor visited the Institute of Mechanics, Peking, in April 1980 (figure 3).

Tan, the Deputy Director of the Institute of Mechanics, chaired the reception of Batchelor's visit. Figure 3 shows their farewell photo after the meeting. As in Cambridge, April was still cold and they were wearing winter clothing. The clothes of the Chinese were still the very politically correct style.

Notably, Batchelor and Tan had met each other 25 years earlier when both of them were at Cornell University for a time. ${ }^{58}$ They had also worked on the same topic (final-period (stage)

58 Report on visit to China under the exchange agreement between The Royal Society and the Chinese Academy of Sciences, 4-23 April, 1980, p. 5, Batchelor Archive. 
decay of grid-produced turbulence), the former in the 1940s, the latter in the 1960s, as already mentioned. Presumably this provided a good basis for discussions.

Just after China opened its doors to the Western world for the first time since 1949, Batchelor did great work for the Chinese fluid mechanics community. He valiantly and enthusiastically opened the way for renewed academic exchange between the UK and China at no advantage to himself. The so-called academic exchange was actually about providing Chinese fluid dynamicists with a window of access to the frontiers of worldclass scientific research and teaching, and also to show the 'spirit of Cambridge' to more Chinese fluid dynamicists. The IUTAM Symposium on Fluid Mechanics 'In the Spirit of G.I. Taylor' was held on the centenary of his birth at the university of Cambridge from 24 to 28 March 1986. The primary purpose of the symposium was to consider whether G. I. Taylor's style of research is still of value today and is still in use. ${ }^{59}$ By analogy with the 'Spirit of G. I. Taylor', the 'spirit of Cambridge' refers to the style of research being created and pioneered by Taylor and Batchelor in Cambridge.

It is notable that Bachelor did not speak about turbulence during his first trip to China in April 1980. Instead he gave lectures on colloidal dispersions there.

The reason for Batchelor's shift from turbulence was noted by Keith Moffatt (FRS 1987):

For the next decade and a half (after the 1950s) Batchelor produced a series of important articles on turbulence until he concluded at the Marseilles symposium of 1961 that the subject had reached an impasse. He turned his talents to micro-hydrodynamics, a field in which he made equally important contributions. ${ }^{7}$

It is unknown whether Batchelor ever tried to steer Chinese scientists away from the topic of homogeneous, isotropic turbulence to other research areas, although his complete omission of the topic when in China would seem to indicate that. Fu Chia and Ching Shen were Batchelor's lecture interpreters for the April 1980 lectures. Those lectures aroused the interest of Ching Shen.

At Peking University Batchelor was welcomed by Guang-Jiong Chou (1918-2019), Head of the Department of Mechanics, and several of his senior colleagues, including T.-F. Sun, whom Batchelor met at Cornell University in 1955, and Chan-Man Fong, a rheologist who had come to China very recently after being a lecturer for 12 years at Reading University. Peiyuan Chou and Batchelor had met each other many times in the West about 30 years previously when they were involved in similar research on the theory of turbulence. Batchelor did not meet Peiyuan Chou at Peking University in April 1980. However, Peiyuan Chou kindly invited Batchelor and Wilma to a grand dinner at the Peking Duck restaurant, together with Keith Hunter (First Secretary at the British Embassy, Peking) and his wife Ann and some members of the staff of the Institute of Mechanics. Batchelor was able to discuss with Peiyuan Chou the participation of Chinese scientists in the International Union of Theoretical and Applied Mechanics, to which China had applied for membership. Peiyuan Chou would be the leader of a delegation of about 18 Chinese scientists to the next International Congress of Theoretical and Applied Mechanics at Toronto in August 1980. Later during his stay in Peking, Batchelor wrote to Peiyuan Chou to seek his support for a proposal for an IUTAM symposium on a specific topic to be held

59 Batchelor, G. K., 'The IUTAM Symposium on Fluid Mechanics in the Spirit of G.I. Taylor', J. Fluid Mech. 173, vi-x (1986), at p. vi, 2nd paragraph, lines 7-10. 
in Peking in 1982 or 1983; it seemed to Batchelor that since the number of Chinese scientists able to travel to conferences abroad during the next few years was likely to be very limited, the next best way of promoting contact was for international conferences to be held in China. ${ }^{56}$

At Tsinghua University, Batchelor was received by Wei Chang (1903-2001), Head of Engineering Mechanics, and Ning Chien (1922-1986), Head of Hydraulic Engineering, and several of their colleagues, and they began with a wide-ranging discussion about current research in fluid mechanics at Tsinghua University and at Cambridge.

At the Institute of Atmospheric Physics, Batchelor was welcomed by its Director, Tu-Cheng Yeh (1916-2013), who struck Batchelor as a person of considerable ability.

At Xi'an Jiao Tong University, Batchelor was received by Gui-Fang Xu, Head of the Department of Mathematics, and Yi-Ming Xiang, Head of the Department of Power Machinery Engineering, and a number of their colleagues.

Batchelor was greeted on arrival at Fudan University by Fu-Lin Jin, Acting Head of the Department of Mathematics, and Jing-Tang Ye, leader of the fluid mechanics section of that department, and several of their colleagues. They took Batchelor to meet Jia-Zhen Tan (1909-2008), the Vice-President of the university. Batchelor presented two lectures, on topic (4) on the first day and on topic (3) on the second day.

On his arrival at Shanghai Jiao Tong University, Batchelor was greeted by the ViceChancellor, Tong-Liang Lin (1930-2019), the Head of the Department of Engineering Mechanics, You-Shen He (1931-2018), the Head of the Department of Applied Mathematics, Ming-Chian Tsao, and several of their senior colleagues.

After his visit to China in April 1980, Batchelor concluded: ${ }^{56}$

The theoretical side, which is an essential part of almost any successful research programme in fluid mechanics, is very weak in most of the institutions that I visited, and strengthening it ought be one of the scientific priorities in China at the present time....

The fact that the visit was not of much direct and immediate scientific value to me is not of first importance. The universities and institutes are in a phase of reconstruction, and before long they will have a great deal to show a visitor. I felt I was able to contribute a little to their plans for the future, and, more importantly, I have made some lasting personal contacts which will yield benefits for both sides in the future. Taking the long-term view, it may be even more valuable to establish scientific contacts and friendships now than at a time when Chinese science is flourishing.

\section{Atmospheric physics delegation from the Academia Sinica in December 1981}

In December 1981, the Royal Society accepted a visit to the UK by a six-person delegation, led by $\mathrm{Tu}(\mathrm{Du})$-cheng Yeh (Ye), Vice-President of the Academia Sinica, and Director of the Institute of Atmospheric Physics, Peking. Other members of the delegation included: Yibing Xie, Chairman, Department of Geophysics, Peking University; Xiaoping Zhou, Head of Laboratory of Severe Conductive Weather, Institute of Atmospheric Physics; Yenzheng Hao (female), Head of Laboratory, Institute of Atmospheric Physics; Yude Wang, Engineer, Deputy Section Head of Scientific Planning Office, Institute of Atmospheric Physics; Chunshu Chen, Second Secretary (Science), Chinese Embassy, London. This visit was conducted under Article 2 of the Royal Society exchange agreement with the Chinese Academy of Sciences. ${ }^{60}$ 
They stayed in Cambridge from 11 a.m. Thursday 17 December to 5 p.m. Friday 18 December 1981. They went to Madingley Rise at 4 p.m. on Thursday 17 December and had dinner at Darwin College on Thursday evening. ${ }^{59}$ Batchelor had enlisted the help of M. E. McIntyre and other members of the staff of DAMTP with an interest in dynamical meteorology to show the atmospheric physics delegation from the Chinese Academy of Sciences the work in progress. The members of DAMTP included: M. K. Davey, Adrian Edmund Gill (FRS 1986), P. D. Killworth, Paul Frederick Linden (FRS 2007), Julian Hunt (FRS 1989), Michael Edgeworth McIntyre (FRS 1990), John Edward Simpson (19152007) and Ching-Sung Wen. Senior Visitors to DAMTP included: C. J. R. Garrett of Dalhousie University, Nova Scotia, and W. W. Hsieh of the University of British Columbia. Gill, Davey, Killworth, and McIntyre gave brief accounts of some current work. Hunt, Linden and Simpson gave brief accounts of current work on environmental fluid dynamics. Yeh (Ye) described some of the work of his institute.

Yeh (Ye) wrote to Batchelor: 'All members of my delegation were very pleased to have such a fruitful discussion with you and your colleagues. It is mutually beneficial not only now but also in [the] future. ${ }^{61}$ In his reply to Yeh (Ye), Batchelor said 'We enjoyed very much the visit that you and your colleagues paid to the Department [DAMTP] in December [1981], and I am glad that you also found it interesting and fruitful., ${ }^{, 62}$

The ' $\mathrm{Tu}(\mathrm{Du})$-Cheng Yeh (Ye) Centenary Symposium: From General Circulation to Global Change' was held in 2016 in Nanjing, China. It was organized by the Institute of Atmospheric Physics, Chinese Academy of Sciences. McIntyre was invited to attend this symposium. He wrote an article related to Yeh (Ye). ${ }^{63}$

\section{BATCHELOR'S PROPOSAL FOR COLLABORATION BETWEEN THE TWO INSTITUTES}

Before Batchelor's visit to the Institute of Mechanics, China, in April 1980, at DAMTP, Cambridge, a $1 \mathrm{~m}$ diameter direct-drive, rotating turntable had been commissioned, and a series of experiments on rotating, stratified fluids was begun in June 1979. Paul Linden and his colleagues used it to examine the stability of isolated vortices in a two-layer flow and to investigate the currents that form adjacent to vertical boundaries in rotating, stratified flows. ${ }^{64}$ Linden felt it was important to further investigate general dynamical problems, rather than to try to model specific situations. This is particularly the case in the area of rotating, stratified fluids, where it is unclear what aspects of a given situation are important. Linden therefore outlined the following topics for possible future studies: (1) isolated vortices in a uniform density gradient; (2) how a vortex that is very large compared with the Rossby radius breaks up; (3) the effect of bottom topography on two-layer flows; (4) the effect of topography on boundary currents; and (5) all of these experiments could be repeated with variations in fluid depth used to simulate the variation of the Coriolis parameter with latitude. ${ }^{64}$

The result of Batchelor's visit to the Institute of Mechanics, China, in April 1980 was that both institutions would soon have well-constructed rotating tables of about $1 \mathrm{~m}$ diameter with fine control of the rotation speed and a full range of auxiliary equipment for the observation of

61 Letter from Du-Cheng Yeh to Batchelor, dated 6 February 1982, Batchelor Archive.

62 Letter from Batchelor to Du-Cheng Yeh, dated 15 February 1982, Batchelor Archive.

63 M. E. McIntyre, 'On multi-level thinking and scientific understanding', Adv. Atmos. Sci. 34, 1150-1158 (2017)

64 P. F. Linden, 'Experiments on rotating, stratified fluids', May 1980, Batchelor Archive. 
flow systems mounted on the table. The rotating table in Cambridge had been in operation for a year, and two projects under the direction of Linden had been completed. The first was an examination of the stability of vortices in a rotating two-layer system, and the second was an investigation of the currents that form near vertical boundaries in rotating stratified flow systems. The rotating table at the Institute of Mechanics, China, had been constructed under the direction of $\mathrm{Fu} \mathrm{Chia}$, and was nearly ready to be used for experimental work. ${ }^{65}$ The two institutes were both engaged in research in geophysical fluid dynamics. Both were interested, in particular, in flow systems which exhibit the combined effects of bulk rotation and of density stratification of the fluid. There are many manifestations of these effects in the oceans and atmosphere, but the emphasis in the research programmes in the two institutions was on basic dynamical processes.

A proposal for research collaboration between DAMTP and the Institute of Mechanics was then prepared by Batchelor with the help of the two principals, Linden and Chia, on 4 July 1980. ${ }^{65}$ The two groups proposed a joint research project on 'the dynamics of rotating stratified fluids', and they hoped that the Royal Society and the Chinese Academy of Sciences would accept this as one of the collaborative projects to be supported under the terms of their Agreement on Scientific Cooperation. ${ }^{64}$ The Cambridge group was a little further advanced with their work, and were in an exciting phase in which interesting possibilities are opening up rapidly. ${ }^{65}$ Although correspondence was useful, some exchange of personnel between the two institutions was seen as essential between the laboratories if the proposed collaboration was to be effective. This led to Chia's visit to Cambridge in 1981. In his confirmation letter to Hao Ting, Director of the Foreign Affairs Bureau, Chinese Academy of Sciences, Beijing, on 31 July 1980, Ronald Keay wrote, 'We would like to support the proposed project and would be grateful if you would arrange Chia Fu's visit either under Article 2 or Article 5(b) of our agreement. ${ }^{66}$

The dynamics of aerosol and hydrosol particles was the second area of collaboration between the two institutes. There were thus two areas of fluid mechanics in which collaboration was already taking place and in which results of interest and value to both sides had been obtained. Batchelor proposed that collaboration should be continued in these two areas, and that other areas of common interest that seemed suitable for collaboration should also be investigated, e.g. magnetohydrodynamics and applications in astrophysics and in the metallurgical industry, physiological fluid mechanics, and industrial fluid mechanics including topics such as two-phase flow and vortex shedding. ${ }^{67}$

In 1982, Batchelor proposed to promote further collaboration between the two institutes. In his second proposal of 29 October 1982, Batchelor wrote:

It is proposed that the existing collaboration between the two institutes in certain areas of fluid mechanics should be extended and formalized. Each of the two institutes is engaged in an extensive programme of research within the broad field of fluid mechanics and there are a number of areas of common interest. The purpose of the collaboration is to enable each institute to take advantage of the human and physical resources of the other and to share new ideas and developments as they arose. ${ }^{68}$

65 G. K. Batchelor, Proposal for research collaboration between the CAS Institute of Mechanics, Peking, and the Department of Applied Mathematics \& Theoretical Physics, University of Cambridge, 4 July 1980, Trinity College Library.

66 Letter, Ronald Keay to Hao Ting, 31 July 1980, Trinity College Library.

67 Ching Sheng, 'Colloidal dispersions and microhydrodynamics', November 1981, Trinity College Library.

68 G. K. Batchelor Proposal for collaboration in research in fluid mechanics, 29 October 1982, Batchelor Archive. 
This collaboration continued.

The draft of Batchelor's second proposal was sent for comment to Tung-Chi Lin of the Institute of Mechanics, Beijing; Ching-Sung Wen of the Anhui Institute of Optics and Fine Mechanics, Hefei; Xue-Zheng Ma of the Foreign Affairs Bureau, and the Chinese Academy of Sciences; and Catherine Donovan, the Royal Society, London. Batchelor's proposal was met with an especially active response among the staff of the Institute of Mechanics working in the fields of geophysical and astrophysical fluid dynamics, though the proposed formalization of the existing collaboration between the two sides, unfortunately, remained unsettled. ${ }^{69} \mathrm{Hu}, \mathrm{Ma}$ and Zhemin Zheng were going to have discussions with Batchelor about his proposals in the UK. ${ }^{68}$ Personal contact between scientists is of special importance for developing scientific collaboration. The proposed duration of the formal collaboration was five years from 1986 to 1990 . Exchange visits were to be arranged lasting six man-weeks per year in each direction. The collaboration would be conducted in the form of lecturing and direct joint research, in addition to constant scientific communications. The collaboration in the areas of common interest such as the research on solar activities, solar-terrestrial physics, oceanic currents and meso-scale eddy modelling, turbulent diffusion in the natural environment, water waves and applied mathematics would be arranged in order of priority. ${ }^{70}$ Keith Moffatt of DAMTP was invited to visit China at his convenience to initiate formalized collaboration. ${ }^{70}$ On 26 November 1985, Wen-Rui Hu, Chairman of the Department of Basic Research of Mechanics, on behalf of the institute, wrote a confirmation letter to Moffatt and Batchelor. ${ }^{71}$ According to Wenrui $\mathrm{Hu}$, Chou, who was his Professor, suggested Hu invite Moffatt to the Institute of Mechanics in 1986. A formal dinner for the reception of Moffatt was held in the People's Great Hall, Beijing. A discussion about the international cooperation was made there. Moffatt's visit to Beijing was important and fruitful. ${ }^{72}$

When Batchelor retired, he continued to work and publish enthusiastically. In his proposal to the Chinese Academy of Sciences in November 1983, Ching Shen wrote:

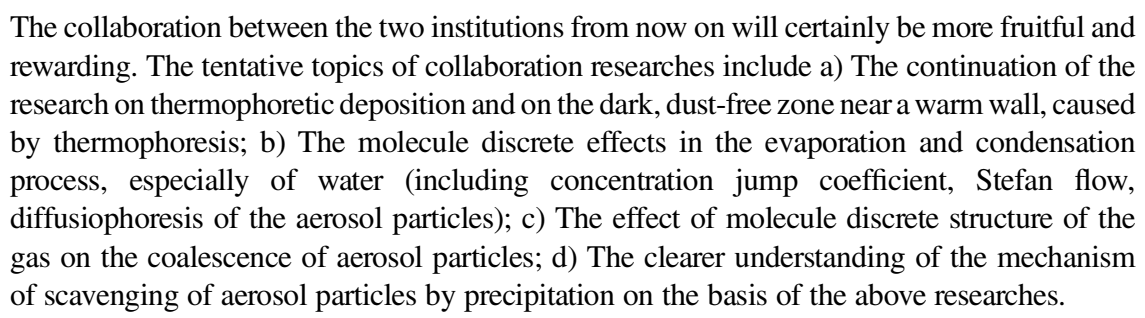

Shen's previous research interest had been in rarified gas dynamics. The mathematical approaches used in problems of rarified gas dynamics are actually the same as those needed in problems of aerosol dynamics, and thus Shen would be able to deploy some valuable techniques in the field of the dynamics of aerosol and hydrosol particle

69 Letter, C. Donovan to Batchelor, 20 October 1982, Batchelor Archive.

70 Proposal for Research Collaboration in Geophysical and Astrophysical Fluid Mechanics between the Department of Applied Mathematics and Theoretical Physics, University of Cambridge, UK, and the Department of Basic Research for Mechanics, Institute of Mechanics, Academia Sinica, China, Batchelor Archive.

71 Letter, Wen-Rui Hu to H. K. Moffatt, 26 November 1985, Batchelor Archive.

72 Wen-Rui Hu, personal communication, 11 October 2019. 
dispersion. Arrangements were in hand for Shen to visit DAMTP from January to July 1983, so as to study the broad field of aerosol and hydrosol dispersions and to lay the foundation for collaborative research after his return. Batchelor hoped that Wen and Shen would be able to co-ordinate their research, despite being rather far from each other in mainland China, after Shen's return from Cambridge.

\section{Batchelor AND his Chinese visiting scholars at CAMBridge in the 1980s}

After Batchelor's visit to the Institute of Mechanics of the Chinese Academy of Sciences, Beijing, China, in April 1980, the academic exchange programme between the Chinese Academy of Sciences and the Royal Society was established. Following the proposals by Batchelor as described above, the programme received full support from the Chinese Academy of Sciences and the Royal Society. From the Chinese Academy of Sciences, Ching-Sung Wen (1933-2015), Fu Chia and Ching Shen were sent as visiting scholars to DAMTP at the University of Cambridge.

Batchelor himself had hosted two Chinese visiting scholars directly from mainland China in the 1980s, namely Ching-Sung Wen (1933-2015), from the Anhui Institute of Optics and Fine Mechanics, Chinese Academy of Sciences; and Ching Shen (1935-2011), from the Institute of Mechanics, Chinese Academy of Sciences. Wen's background was in cloud physics and he had worked closely with Batchelor on problems of droplet growth by coalescence during a two-year visit to DAMTP from October 1979 to 1981. They published their results in two joint papers. ${ }^{73,74}$ At the invitation of Batchelor, Shen visited DAMTP from January to July 1983. Shen took part in the academic activities of the Colloidal Dispersions and Microhydrodynamics group of DAMTP and did research on the concentration jump boundary condition in binary rarefied gases. The collaborations were successful, as shown in the joint paper. ${ }^{75}$

Fu Chia, who was from the Institute of Mechanics, Chinese Academy of Sciences, Beijing, was officially hosted by Paul Linden, from December 1980 to August 1981, at the same period as Wen. Chia and Linden published their work. ${ }^{76}$

As recalled by Fu Chia, in the 1980s, when Chinese visiting scholars arrived in Cambridge as relatively unsophisticated 'country men', they were full of surprise and even amazement not only at the unfamiliar social and cultural aspects of the West, but also the academic aspects. Batchelor meticulously cared about the Chinese guests. He understood that they felt unfamiliar with the West and even embarrassed and poor. Batchelor invited Fu Chia to a formal dinner at Trinity College and brought him to the Summer Soirée at the Royal Society in London. Newly arrived Chinese visitors at Cambridge were invited to the houses of Batchelor, Linden, and Adrian Edmund Gill (1937-1986, FRS 1986). Batchelor

73 G. K. Batchelor and C. S. Wen, 'Sedimentation in a dilute polydisperse system of interacting spheres. Part II. Numerical results', J. Fluid Mech. 124, 594-528 (1982).

74 C. S. Wen and G. K. Batchelor, 'The rate of coagulation in a dilute suspension of small particles', Sci. Sin. 28, 172-184 (1985).

75 G. K. Batchelor and C. Shen, 'Thermophoretic deposition of particles in gas flowing over cold surfaces', J. Colloid Interface Sci. 107, 21-37 (1985).

76 F. Chia, R. W. Griffiths and P. F. Linden, 'Laboratory experiments on fronts. Part II: the formation of cyclonic eddies at upwelling fronts', Geophys. Astrophys. Fluid Dynam. 19, 189-206 (1982). 


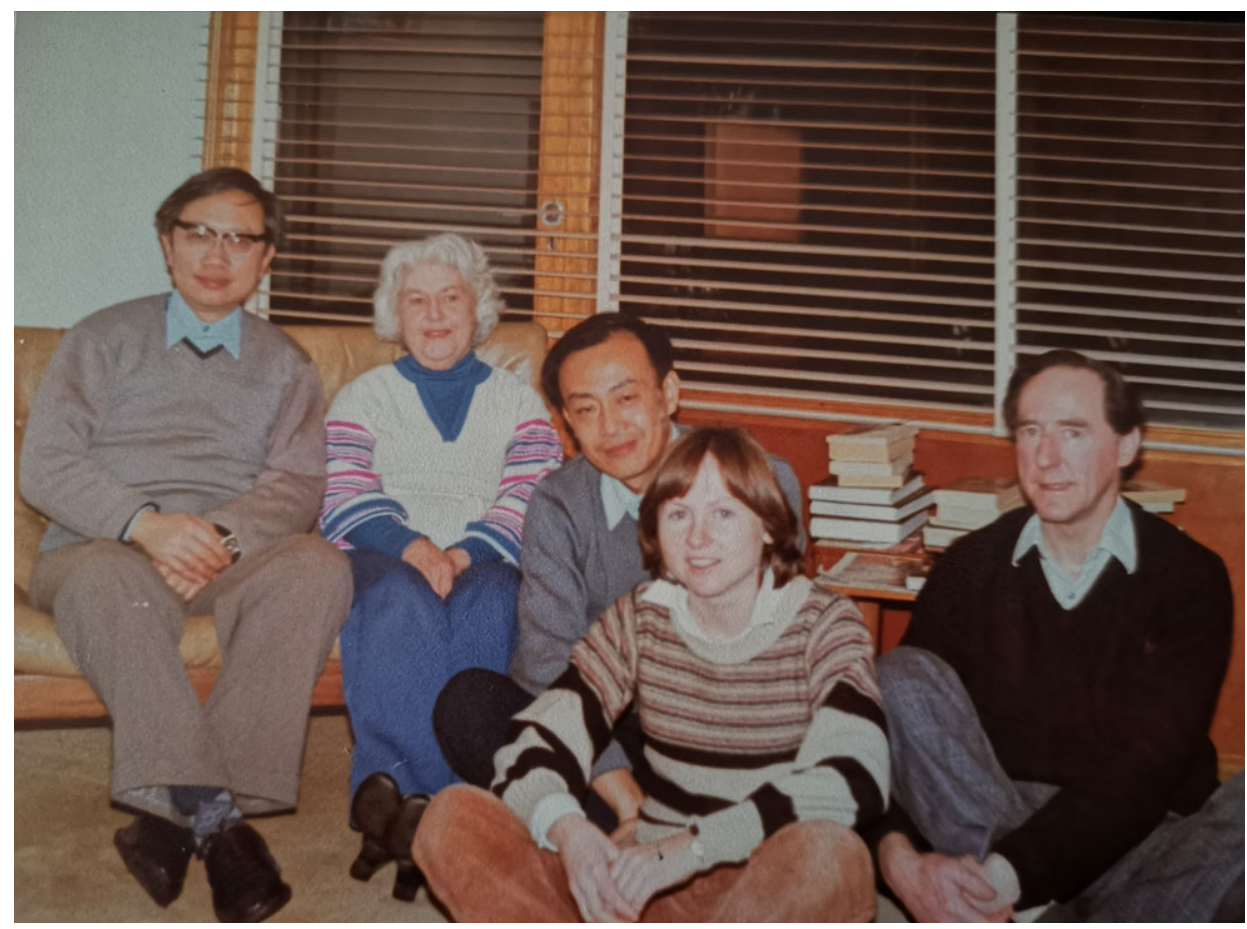

Figure 4. Ching-Sung Wen, Wilma Batchelor, Fu Chia, Bryany Batchelor and George Batchelor in Batchelor's house about December 1980. (Online version in colour.)

gave them advice on how to make friends and how to live and study in England. As guests of Batchelor, they received a warm reception, thoughtful care and help, enabling them to settle in quickly in a welcoming atmosphere.

For example, in December 1980, Batchelor invited Wen and Chia to his house and introduced new friends to them before and after Christmas (figures 4 and 5). Batchelor also invited Chia to visit Blickling Hall, Norfolk, together with Claire and Wilma (figure 6). Chia was also looked after very well by Batchelor (figure 7). When Chia had just bought his camera, Batchelor was happy to be Chia's camera 'model' (figure 8).

From DAMTP, Paul Linden, John Edward Simpson, Keith Moffatt and Julian Hunt visited the Institute of Mechanics, Chinese Academy of Sciences, Beijing, and other universities and institutes in China. Simpson visited China in September 1983. Linden visited China in June 1984. Moffatt spent three weeks of September 1986 in China.

Batchelor had other Chinese visitors, including Ted Wu, an American-Chinese fluid dynamicist from the California Institute of Technology, Pasadena, in the 1970s, Chuan F. 'Tony' Chen, an American-Chinese fluid dynamicist from the University of Arizona, from 1986 to 1987, and Song-Ping Zhu, an Australian-Chinese fluid dynamicist from the University of Wollongong, Australia, from 1994 to 1995.

Tony Chen was born in Tianjin, China, in 1932 and passed away in 2019. In 1996, he nominated Batchelor for the G. I. Taylor Medal of the Society of Engineering Science (SES). The nomination package included the enthusiastic recommendations of Andy 


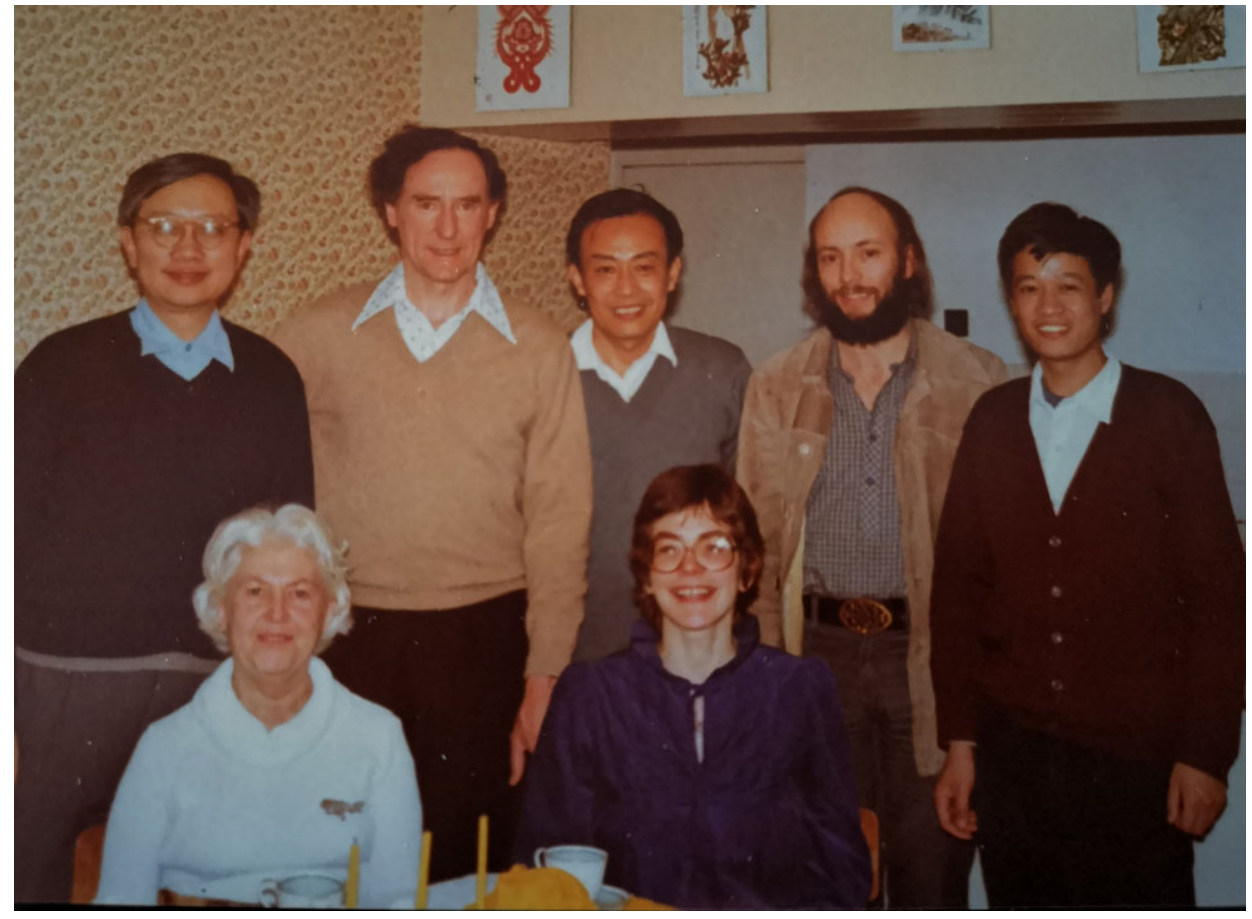

Figure 5. Back row: Ching-Sung Wen, George Batchelor, Fu Chia, Paul Linden, unidentified man. Front row: Wilma Batchelor, Diana Linden (1944-2019), in Batchelor's house about December 1980. (Online version in colour.)

Acrivos, Tim John Pedley (FRS 1995) and David Crighton (FRS 1993). ${ }^{77}$ Tom Chang of MIT, Chairman of the SES Awards Committee, informed Chen that 'the full Nominating Committee and the full Board of Directors have unanimously voted to award the 1997 Taylor Medal to George Batchelor'. ${ }^{78}$

Other Chinese fluid dynamicists who contacted Batchelor regarding possible visits to DAMTP in the 1980s included: Sang-Chun Shieh ${ }^{79}$ and Zhi $\mathrm{Gao}^{80}$ from the Institute of Mechanics, Academia Sinica, Peking, although visits did not occur. Given that turbulence was Shieh's main field of work, Batchelor suggested Shieh contact Alan A. Townsend. ${ }^{81}$ Two other Chinese fluid dynamicists who contacted Batchelor regarding possible visits to DAMTP in the 1980s were Shi-He Liu ${ }^{82}$ from Wuhan University of Hydraulic and Electric Engineering, Wuhan, and Youming Yuan ${ }^{83}$ from the Beijing Institute of Aeronautics and Astronautics, Peking. Batchelor introduced them to Hunt, who accepted them as visitors. ${ }^{84}$

\footnotetext{
77 Tony Chen, e-mail to Batchelor, from cfchen@abacus.AME.Arizona.EDU, 20 June 1996, Batchelor Archive

78 Letter from Tom Chang to Tony Chen, Batchelor Archive.

79 Letter from Sang-Chun Shieh to Batchelor, dated 12 December 1981, Batchelor Archive.

80 Letter from Zhi Gao to Batchelor, dated 17 October 1988, Batchelor Archive.

81 Letter from Batchelor to Sang-Chun Shieh, dated 5 February 1982, Batchelor Archive.

82 Letter from Shi-He Liu to Batchelor, dated 1 February 1988, Batchelor Archive.

83 Letter from Youming Yuan to Batchelor, dated 30 January 1988, Batchelor Archive

84 Letter from Julian Hunt to Shi-He Liu, dated 11 February 1988, Batchelor Archive.
} 


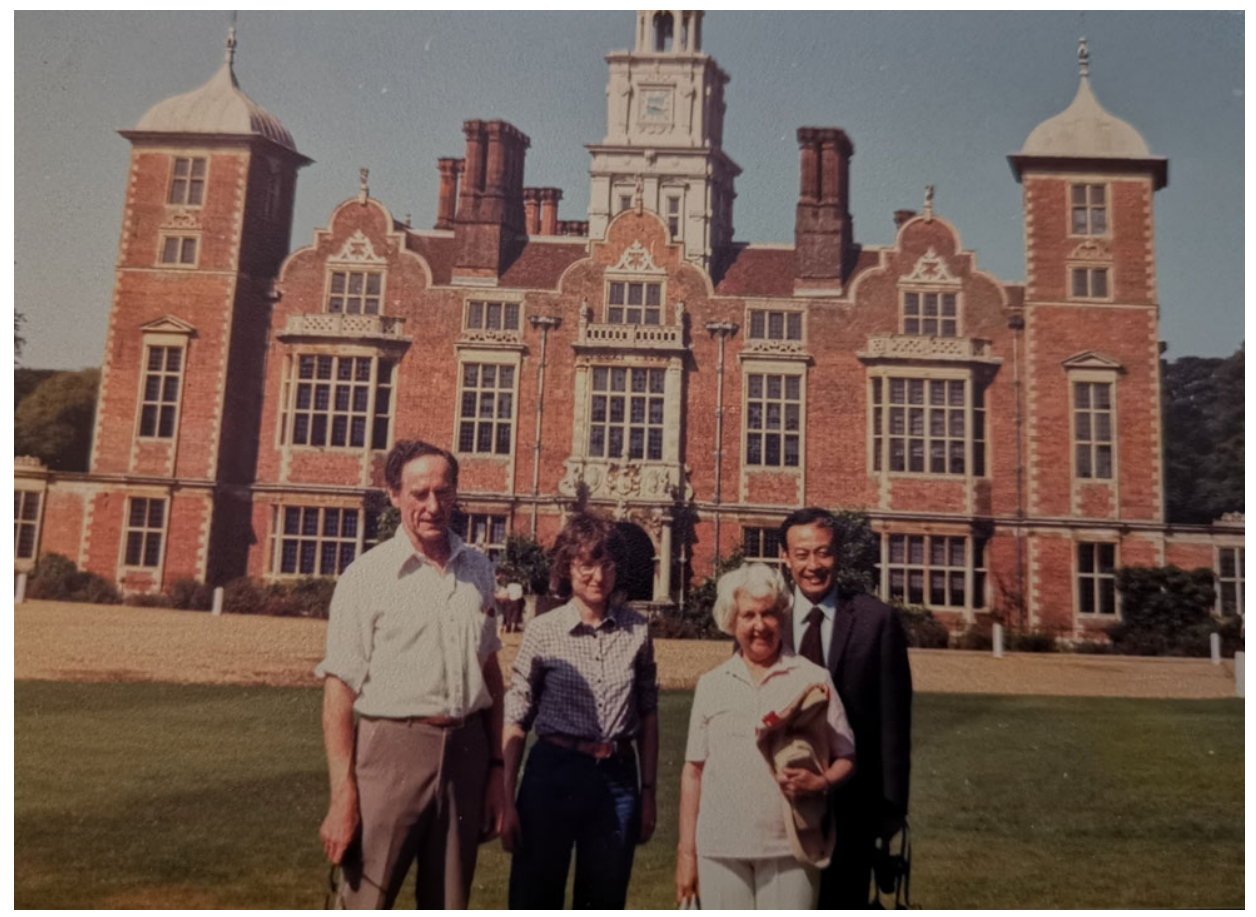

Figure 6. George Batchelor, Claire Batchelor, Wilma Batchelor and Fu Chia visiting Blickling Hall in Norfolk, UK, about May 1981. (Online version in colour.)

Batchelor's An introduction to fluid mechanics ${ }^{53}$ was translated by Ching Shen and Fu Chia into Chinese and published by Science Press, Beijing, China, in 1997. The book was of interest to Chinese fluid dynamicists, including postgraduate students and university lecturers and university/institution research professors. Batchelor's book has been translated into at least five different languages since the 1980s, including Russian, Italian and Chinese (simplified characters). Other licensed translations were in Spanish, Japanese and Chinese (Taiwan), and there was an unlicensed Chinese translation from the 1970s. ${ }^{85}$

After his return to China, especially in his later years, Wen wrote several Chinese articles to introduce DAMTP and Batchelor to Chinese fluid dynamicists. ${ }^{86}$ These were assembled into his slim book in Chinese entitled Exploring Cambridge. ${ }^{87}$

It is evident that generously hosting these Chinese visitors, among others, and exchanging research ideas/methodologies either directly or indirectly helped their academic career, as demonstrated in their later high-quality international publications in the field of fluid mechanics.

85 David Tranah (Editorial Director, Cambridge University Press), personal communication, Monday, 27 October 2019.

86 C. S. Wen, 'Under the supervision of Professor Batchelor. I' (in Chinese), Mechs Engng 31, 90-101 (2009), C. S. Wen, 'Under the supervision of Professor Batchelor. II' (in Chinese), Mechs Engng 31, 83-87 (2009), C. S. Wen, 'To inject the physics into mathematics' (in Chinese), Mechs Engng 32, 83-87 (2010).

87 C. S. Wen, Exploring Cambridge (in Chinese), (Metallurgical Industry Press, Beijing, 2011). 


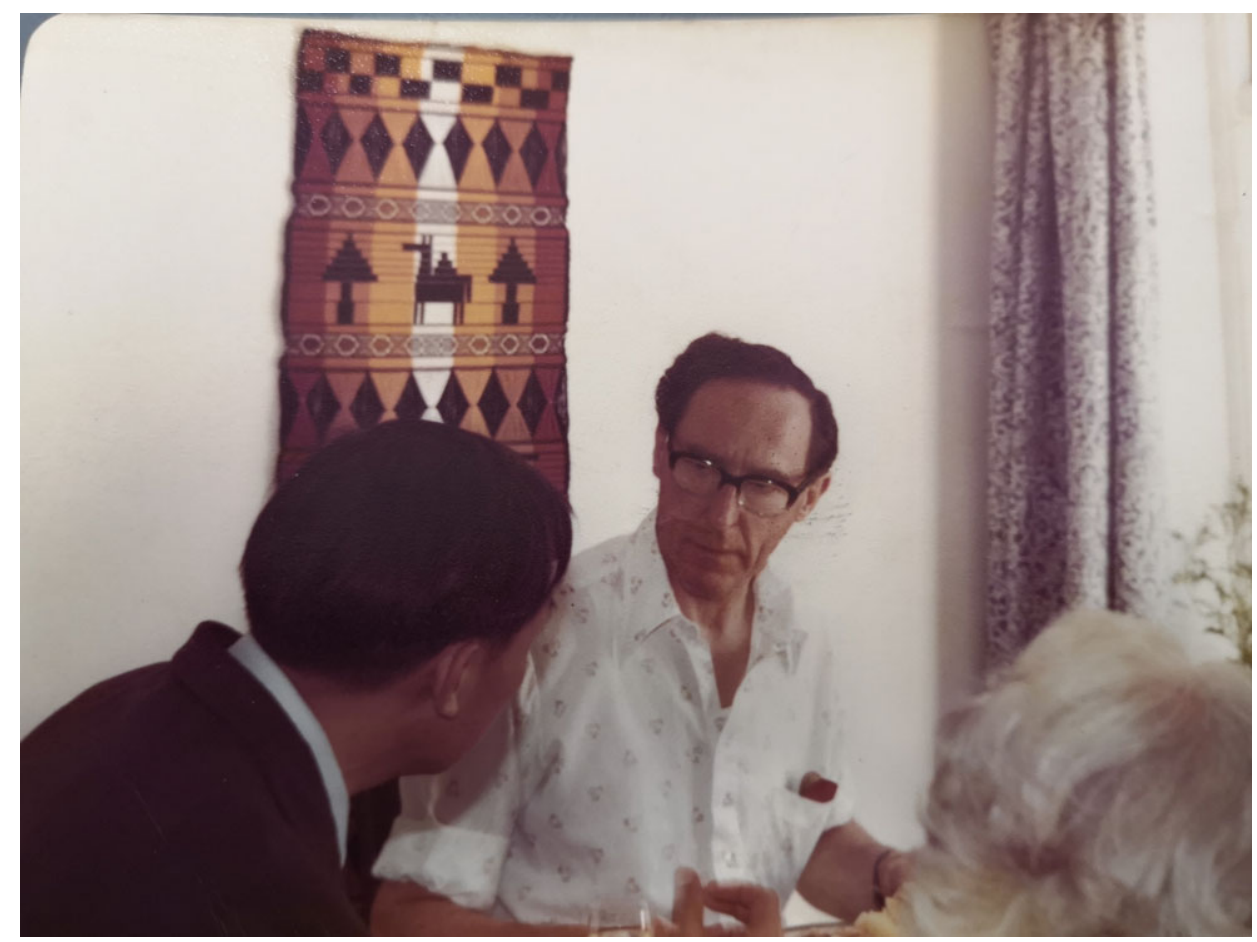

Figure 7. Batchelor dining with Chia and Wilma. (Online version in colour.)

\section{Batchelor's meeting with a Chinese delegation at Cambridge in May 1981}

To have the applications of a science, the science itself must exist. ${ }^{88}$

In the 1980s, China sought to learn about scientific management from Western countries such as the UK. At 2 p.m. on 12 May 1981, ${ }^{89}$ Batchelor, the Head of DAMPT, Cambridge, had a three-hour meeting in his office with Kuo-wei He, from the Education Section of the Chinese Embassy in London, Suhui Deng (1942-1999), from the Chinese Academy of Sciences, Changgeng Cui, from the Institute of Physics, Chinese Academy of Sciences, who was a visiting scholar at the Department of Materials, University of Cambridge, Chia and Wen. After the meeting, Batchelor led them to visit the fluid dynamics laboratory. This meeting covered many topics. For some reason, however, the tape recording was not successful and it had to be done again. Batchelor was patient enough to re-answer the questions from the Chinese delegation once more. The meeting was chaired by He. The following contents are extracts based mainly on the second, 33-minute tape recording. Note that the following lines may not be verbatim. The questions from the Chinese delegation, taken seriously by Batchelor, however, were rather short and thus are briefly presented. 


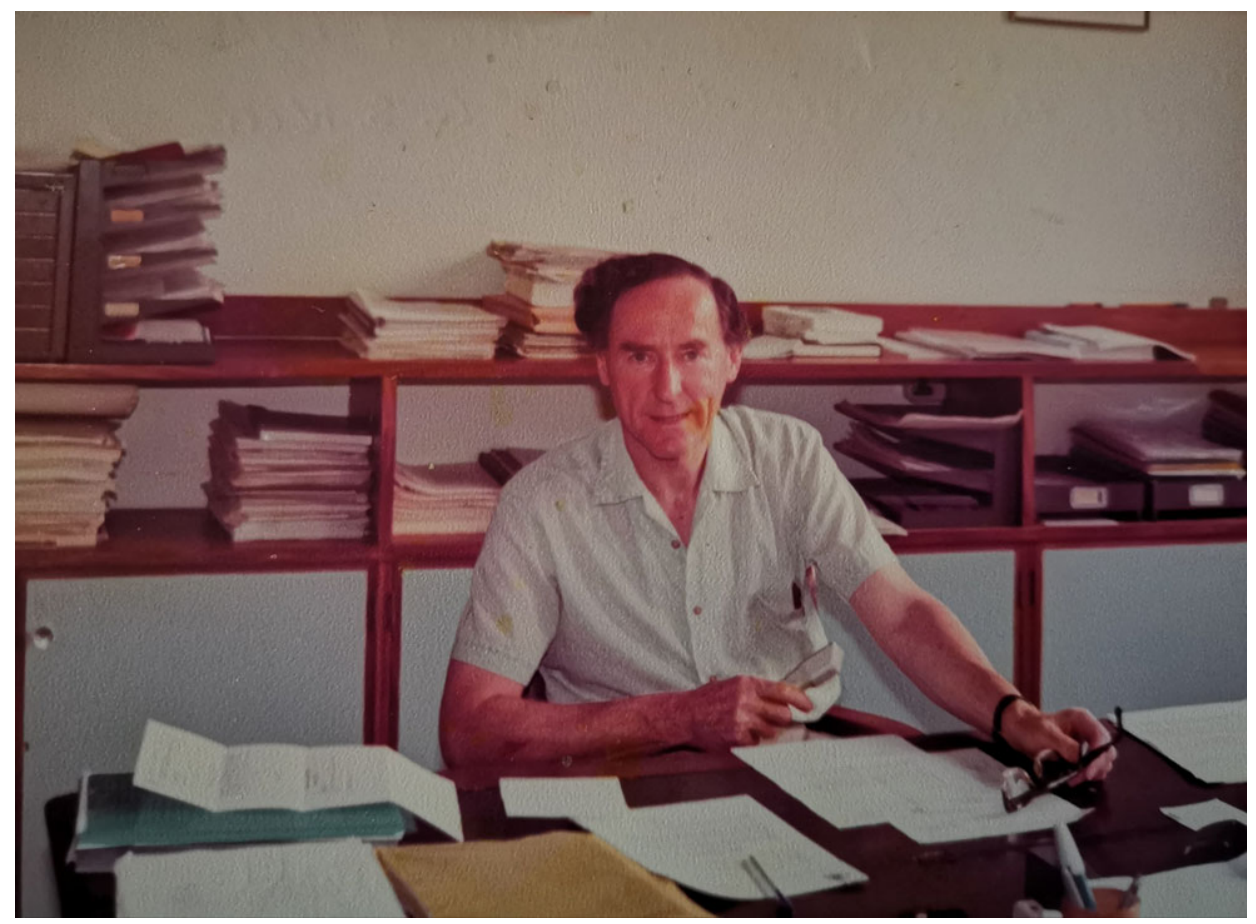

Figure 8. Batchelor in his office in Cambridge about June 1981. (Online version in colour.)

Question from Chinese delegation: Unclear.

Batchelor's reply: This is a question which worries us very much, because when young students come to Cambridge first, all they know is that they are interested in mathematics. They find that they are good at it and they like to study it. Pure mathematics has very strong attractions for them. It has a beautiful and logical structure. It is very elegant. It is precise. It does not have the uncertainties and the untidiness of applied mathematics. It does not require some knowledge of physical background. So, for the young students, pure mathematics is very attractive, and we do have to work quite hard in the teaching of the first three years to make our applied mathematics courses attractive too. We find that as they get higher up the university tree, more and more of them are attracted to applied mathematics. In the first year, pure mathematics attracts most. When it gets to the third year, it may be $50-50$. The fourth year, we find more coming to applied. It is a gradual process, and I think it comes from the gradual appreciation of the attractions of scientific application. At first, it is too hard for them. I do not think they see the interests and the beauty of applications to physics and engineering. But gradually, they come to see it.

Question from Chinese delegation (Deng's question): What are your views of pure mathematics and applied mathematics?

Batchelor's reply: It is precisely the reason why at the very beginning of the formation of the department, I wanted this common interest in physical phenomena to be the unifying feature. I wanted to make it clear to everyone that applied mathematics was not just a case of taking some mathematics and solving an equation of which the variables happen to represent some physical quantities. I wanted to make it clear that it is much more than that. You have got to inject some physical thinking as well as mathematical thinking. 
And initially students do not understand that. It is not until they get to about the fourth year of study they begin to see. Even then, they don't all see it.

Question from Chinese delegation (He's question): Since applied mathematics is close to physics, it is not so good to change pure mathematicians to do applied mathematics.

Batchelor's reply: You must train them from the beginning. What's more, the training should not be done by pure mathematicians. Because without intending to do so they are likely to produce the same approach that they themselves favour. You must have the teaching done by people who are primarily interested in the science.

Question from Chinese delegation (He's question): Why do people work so hard here?

Batchelor's reply: It is partly a matter of size. The bigger the organization the more difficult it is to get something done quickly. It is the same everywhere. If you go to the engineering laboratory where they have hundreds of technicians in the workshop. I think, probably, you could not get something made just from a little sketch. They would say: you must give it an order number, and you must make a drawing, and you must pass it in to the head of the workshop. He puts it on to a priority sheet, and maybe, later, it's passed on to the person who operates the lathe. I think it is a matter of scale. We keep things small partly because you get more flexibility. And also the people who do the work have more direct interest in what they are doing because they see the results of their work being used. They see them in the experiments. There is a lot to be said for "small is beautiful" in research. Of course, some institutes must be large. It is inevitable. But you can nevertheless create the smallness by decentralization of resources. For instance, here, we decentralized the secretarial work. Each research group has its own secretary. There is no central place where you may take something for typing or reproduction. Each group has its individual secretary who looks after them and does the secretarial work. That, it seems to me, is better because the secretary learns about the habits and wishes of the small research group, and they like the personal connection which is possible. Then equally it seems to me you could decentralize the workshop facilities. Here we have only two technicians anyway. So no need to decentralize that. But in the Institute of Mechanics, I am sure that some machine tools could be moved to be near the laboratories, and maybe one technician should be available to do quick jobs and simple ones. You get quick service and I think you also get more involvement on the part of the person.

But this was in the context of why people seem to work so hard. I think our technicians would all go at 5 p.m. when their working day is finished. This is very different from research people. I think that is because there is such a direct connection between the people in the laboratory who are doing their experiments and the technicians. I think it is the same for the secretaries. The secretaries, I think, are willing to help because they are involved with the people in the little group that they look after. In this respect, I do not think British people are any different from Chinese people. It is a matter of how the work is organized. I think we, perhaps, have the advantage here that we do not pay much attention to administrative matters. There is not very much bureaucracy. Here in this department the only person to help with the administrative work, records, accounts and all such things is my secretary. That is all. She controls expenditure. Well, she doesn't control it, but she monitors and records expenditure, several hundred thousand pounds per year, which is quite a lot of money. And the records for a hundred and forty people. Of course, there are the central offices of the university. They do a lot too but locally that makes it easy. There is not much apparatus of administration. You find more in engineering.

Question from Chinese delegation (He's question): There has been dispute about basic science and technical science. What is mechanics?

Batchelor's reply: As to the basic question which you say is being disputed, I would say 
that mechanics is both. I do not see how you could argue that it is one or the other. Of course, it is a part of physics, and there are some fundamental laws. Newton's law of motion is part of basic science. It is one of the foundations of our understanding of dynamics. On the other hand, mechanics is also widely applied in engineering and indeed other aspects of society, and of course, in some parts of science, mechanics is applied widely in oceanography and meteorology, and in astrophysics, as well as in the making of products like aeroplanes, and extraction of oil, and such matters. And I do not see why there should be dispute. I mean it does not seem to me a sensible question. The answer is so obvious that there are both aspects. Maybe, what people in your institute are really asking, is: should we be engaged in the basic research? or should we be engaged in technological research?

What should we do? Well, your institute may have some obligations, some instructions and some guidelines from the Academy of Sciences. I cannot tell. If you are asking the same question about a university department, then, I would say that you cannot successfully be engaged in technological research in a university department like this one. It needs many people with a knowledge of industry and technology: people whom we could not employ in this department because they would not be suitable for the teaching of undergraduates. You see, the people we employ here are people who can teach undergraduates, and the technologists could not teach our mathematics students. So, for us, there is no choice possible. It must be the basic aspects. But at the same time, this variation in the nature of mechanics work seems to me a continuous spectrum. It is not just two separate streams. It is a very wide stream with one extreme there and one extreme there, and even though our work would have to be directed mainly towards basic mechanics simply because we do not have the technological knowledge to do otherwise. Even though we stick to the neighbourhood of this side we still sometimes have contact with the other side because the two are connected.... Julian Hunt's work on environmental mechanics. He is partly an engineer, and he understands these matters. He looks at the applied science area, and he uses it as a source of stimulation. He sees new problems which are being thrown up by the technological application, and he says "this is a good problem; we must investigate that because it will be so useful." I like to think that even though we are more on one side we keep our eye on the technology as well .... And we have some research contracts from an oil extraction firm. And perhaps contracts in the department from other industrial firms. So there is a connection, and it's a connection which I want to expand, too. In the next few years, I expect British universities to be rather short of money, and I think that in this Department what we will do is to try to get more money from industrial sources. I think that it is an area where there is very much room for growth. A few people in the Department will become interested in industrial problems and could bring a lot of money in the shape of research contracts. And in that way we will compensate for any shortage of money from University sources.

Question from Chinese delegation (He's question): What do you think of the models of the Russian Academy of Sciences and Cambridge University?

Batchelor's reply: Science needs more freedom. The Russian system is, of course, not very old. It was instituted after the Revolution. The Academy of Sciences is old, but before the Revolution it had a quite different function and it was completely different in character. Before the Revolution, it was a collection of distinguished individuals; it was a society, a little bit like the Royal Society, of people who had become outstanding in science. But after the Revolution, it was made of an instrument of government, and it was specifically entrusted with the task of organizing the scientific resources of the country. The intention of the government was that by setting up these research institutes they would be able to regulate the scientific work in such a way that it would be useful to society. I 
think this was the idea: to make scientific work more responsive to social needs. If it was left to universities, and individuals, research might go in any direction. It might be brilliant but it wouldn't produce the technology of coal mines, and electrification, and chemical industry, and all those that were badly needed in Russia in the period after the Revolution. Well, like so many things in USSR, it has gone too far. Now it is gone so far that the universities are greatly weakened because a very large part of the money for scientific research goes to the institutes, and the institutes are strongly controlled by the Academy of Sciences from above. I think that it is very restrictive. And it runs up against the basic problem that you cannot control scientific invention and discovery. You can invest in technology. You cannot invest in scientific advances in the same way. Of course, if you give money to many scientists, that undoubtedly will produce results, but you cannot set up an institute and expect to get advances in a particular field. Science simply is not predictable like that ... I cannot give you money so that you will discover a new formula, for cure of the common cold. What you must do is to spread the money very widely over scientists over a range of fields and wait for the advances to come. Wait for the fruits to develop. It seems to me in USSR, they try to predict too much. They lay down a programme for the different institutes. I don't think that is the best way for science.

In America, a much larger proportion of all the basic science research is done in universities, just as here. There are some industrial laboratories financed by firms like Bell Telephone and General Electric. But, just as here, I think that the science is distributed over a very large number of university centres, and that work is supported by the central government and also by the various state governments, and also by the National Science Foundation and other bodies, much the same as in this country. And it is not regulated. There isn't a plan for scientific discovery. They encourage certain broad fields, but there isn't a detailed plan calling for advances in this or that. And I don't think they try to predict what will come out of the investment. I think, if we are speaking about basic research as distinct from technology for a particular objective, then the maximum freedom the better. The maximum freedom in the hands of good people: it is correlated with the quality of the people.

On Monday 25 October 1982, Mr Hu and Ms Xuezheng Ma, from the Chinese Academy of Sciences, Beijing, visited Batchelor in Cambridge. They intended to have discussions on whether Batchelor's proposals for collaboration with the Institute of Mechanics could be made more formal or not. ${ }^{90}$ They had some sort of formal agreement in mind, i.e. with a specific plan of visits for the future. ${ }^{91}$

On another occasion, Batchelor expressed his view of applied mathematics. After Julian Hunt's reading of the draft of this article, he suggested the author include the following reference to Batchelor's remark to him that the best definition of applied mathematics, including fluid mechanics, was that given by Henri Poincaré, which Hunt found more recently had also been expressed succinctly by the English novelist Charles Dickens: ${ }^{92}$

Henri Poincaré (1854-1912), the famous French mathematician and astronomer, had a similar concept, as he explained in Science \& Method, ${ }^{93}$ when he explained how "success in mathematical research is not only when a lengthy calculation should lead us

90 Letter from Ma Yuan-sheng to G. K. Batchelor, April 10, 1986, Batchelor Archive.

91 Letter from G. K. Batchelor to Ma Yuan-sheng, April 16, 1986, Batchelor Archive.

92 J. C. R. Hunt, 'Dickens and Science by Julian Hunt (1960)', Trinity Annu. Rec. 120, 120-127 (2012).

93 H. Poincaré, Science and hypothesis (Walter Scott, London and Newcastle-upon-Tyne, 1905). 
to a simple and striking result, but that we are not satisfied until we have shown that we might have foreseen ... its most characteristic features. Then the semi-intuitive result might be adapted to other problems of a similar nature-preferably with simple arguments summarized in a few lines." 92

Charles Dickens' more profound and ambitious objective, in which he preceded Henri Poincaré's Science \& Method by 50 years, was that science should inform the public so effectively that it would enable those who became interested in science to explore for themselves the wider implications of scientific ideas. ${ }^{94}$

When Hunt showed Poincaré's book to Batchelor in Cambridge, Batchelor said this should be the aim of all of us (in applied mathematics!). ${ }^{94}$

Furthermore, what is the philosophy of Batchelor's school of fluid mechanics? In the preface of Batchelor's monograph, ${ }^{11}$ he stated that 'It is my belief that applied mathematics, or theoretical physics, is a science in its own right, and is neither a watereddown version of pure mathematics nor a prism of physics. The problem of turbulence falls within the province of this subject, ..., to the task of understanding the phenomena.' At the age of 74 , G. I. Taylor wrote to Batchelor that he (Taylor) resolved 'to learn some more physics'. 95 Batchelor's philosophical inspiration can be best shown by his view that 'You have got to inject some physical thinking as well as mathematical thinking.' In his review of the book Fluid dynamics for physicists, Linden expresses his view that 'the difficulty with fluid mechanics is in the underlying physics'. ${ }^{96}$ On 23 October 2012, John Hinch, a student of Batchelor's, wrote on my copy of Batchelor's monograph ${ }^{11}$ on homogeneous turbulence: 'George Batchelor was my research supervisor \& taught me about suspension not turbulence, but more important taught me to think deeply about the physics.' As a suggestion for the future development of mechanics in China, imagination is a very important part of all sciences, including mechanical sciences as Pedley said in an interview just after the International Congress of Theoretical and Applied Mechanics (ICTAM) closing ceremony on 24 August 2012. ${ }^{97}$

\section{Batchelor at the Second Asian Congress of Fluid Mechanics in 1983}

From early in his scientific career Batchelor had travelled widely to conferences around the world. For example, Batchelor travelled to the turbulence symposium at the Sixth International Congress for Applied Mathematics held in Paris during 22-29 September 1946, where he introduced the works of Kolmogorov, ${ }^{31,32}$ Onsager, ${ }^{98}$ von Weizsäcker and Heisenberg, ${ }^{99}$ in 1946 , as yet unpublished ${ }^{100}$ (but published later, i.e. von Weizsäcker, ${ }^{101}$

94 Available at: https://www.gresham.ac.uk/lectures-and-events/charles-dickens-and-science (accessed 3 November 2019).

95 G. Batchelor, The life and legacy of G. I. Taylor (Cambridge University Press, 1996).

96 P. F. Linden, 'Reviews of Fluid dynamics for physicists. By T. E. Faber. Cambridge University Press, 1995. 440 pp.', J. Fluid Mech. 325, 440-443 (1996), p. 441, paragraph 2, lines 2-3.

97 L. Xin, 'Mechanics is to look at interesting phenomena and inspire imagination. An interview with Prof. Timothy J. Pedley', Bull. Chin. Acad. Sci. 26, 284-285 (2012), p. 285.

98 L. Onsager, 'The distribution of energy in turbulence' (Abstract), Phys. Rev. ii 68, 286 (1945).

99 W. Heisenberg, op. cit. (note 24).

100 G. K. Batchelor, 'Double velocity correlation function in turbulent motion', Nature 158(4024), 883-884 (1946).

101 C. F. von Weizsäcker, 'Das spectrum der turbulenz bei großen Reynodsschen zahlen', Z. Phys. A Hadrons Nuclei 124, 614727 (1948). 
Heisenberg $^{99}$ ); to a symposium on naval hydrodynamics in 1956 in Washington, DC, USA; ${ }^{102}$ to the famous Marseilles turbulence symposium in 1961 in France; to Moscow in 1964; to the International Symposium on Two-phase Systems in 1971 in Israel; to the International Symposium on Modern Developments in Fluid Dynamics in Honour of the 70th Birthday of Sydney Goldstein in 1973 in Israel; to Japan and Australia in 1977-1979; and to the International Symposium on Continuum Models of Discrete Systems in Germany in $1979^{103}$ and China in 1983.

The Asian Fluid Mechanics Committee was jointly founded by Peiyuan Chou (China), Roddam Narasimha (FRS 1992) (India) and Hiroshi Sato (Japan) in 1980 in India. It aims to advance research in fluid mechanics in Asia through interaction and exchange of information between scientists and engineers in the field of fluid mechanics. It became a member of IUTAM soon after its founding.

After the opening of the academic exchange between the Chinese fluid mechanics community and DAMTP, in April 1980, the Second Asian Congress of Fluid Mechanics was able to invite Batchelor to attend. The congress was undoubtedly enlivened by the way in which Chinese fluid dynamicists responded to Batchelor because of his charisma.

The congress, which was co-chaired by Chou and Tung-Chi Lin (1918-1993), was held on 25-29 October 1983 in Beijing, China. There were 205 participants, including 86 international participants. More than 200 papers discussed various topics, including turbulence and flow stability, transonic flow, shock waves, boundary layers, aerodynamics, gas dynamics, water waves, hydrodynamics, hydraulics, computational fluid mechanics, low Reynolds number flow, vortex, wake and jet flow, geophysical and astrophysical flow, two-phase flow, non-Newtonian flow, flow through porous media, magnetohydrodynamics, physico-chemical flow, and bio-fluid mechanics.

There were six invited papers, including 'Galaxies, turbulence, and plasmas' by Chia-Chiao Lin; 'Cognition and description of patterns in turbulent flows' by Hiroshi Sato; 'Laminarturbulent transition: the intermittency revisited' by R. Narasimha; 'Observations on transition of the unsteady pipe flow' by A. K. M. F. Hussain; 'Fluid mechanics serving hydraulic engineering in China' by Bingnan Ling. ${ }^{104}$ Batchelor presented an invited talk entitled 'Sedimentation: a review of developments in a classical problem' (figures 9 and 10).

At the beginning of his talk, Batchelor made the following remarks: ${ }^{105}$ 'I have spent a significant part of my working life in promoting international collaboration mainly in Europe and it is very pleasant as well as a privilege for me now to be regarded temporarily as an honorary Asian.'

After his talk, Batchelor carefully and patiently answered the questions from the audience (figure 11). During a break in the congress, in the front of the Friendship Hotel, Beijing, Batchelor was delighted to have his photograph taken with a number of participants from the Institute of Mechanics, Chinese Academy of Sciences, and other international participants (figure 12).

This was Batchelor's second visit to China. Batchelor was the centre of attention and photography from the participants. After his talk, Batchelor spoke to Wen about this, and Wen said to Batchelor that he was truly the star of the congress. ${ }^{106}$ The Proceedings,

102 M. Eckert, 'Turbulence before Marseille 1961', J. Turbulence 13, 1-25 (2012), p. 16, 2nd paragraph.

103 List of files complied by Keith Moffatt, pp. 28-29, Batchelor Archive.

104 T. C. Lin (ed.), Proceedings of the Second Asian Congress of Fluid Mechanics, 25-29 October, 1983 (China Science Press, Peking and VNU Science Press, Utrecht, 1984).

105 Tape recording 2, Batchelor Archive.

106 C. S. Wen, op. cit. (note 86). 


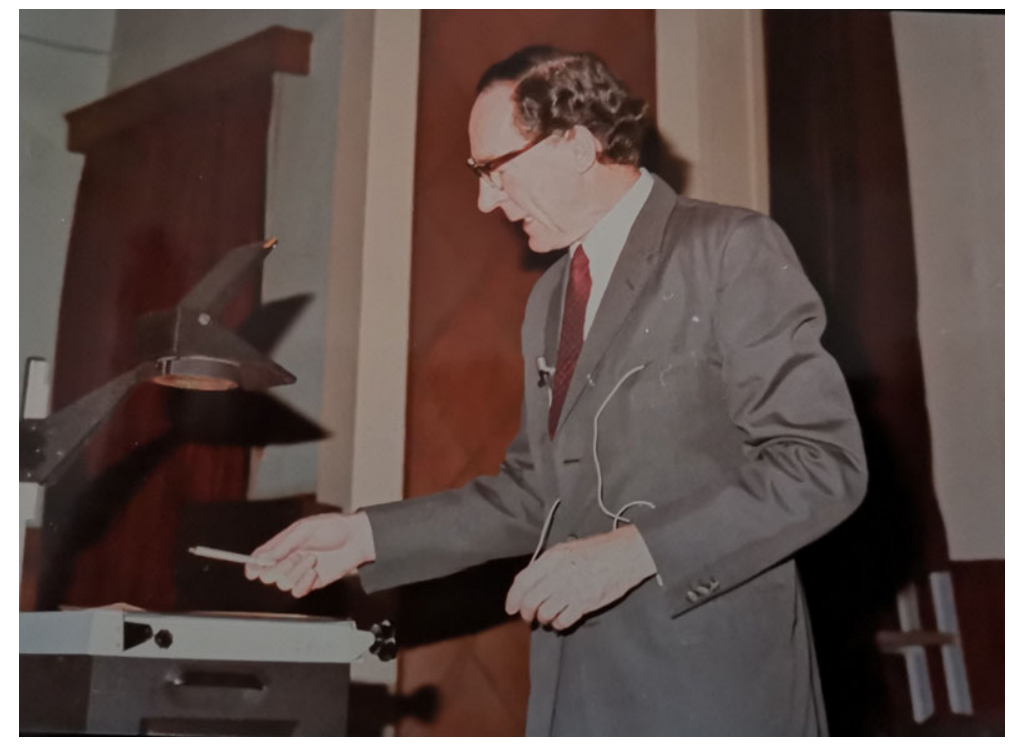

Figure 9. Batchelor (facing the audience) presenting an invited talk at the Second Asian Congress of Fluid Mechanics, on 25 October 1983, Peking. (Online version in colour.)

which were jointly published by China Science Press, Peking, and VNU Science Press, Utrecht, gives a comprehensive picture of the state of the art was well as of recent developments in fluid mechanics in China and in other Asian countries. Western fluid dynamicists are likely to find some interesting and novel papers in their particular area. ${ }^{107}$

There were a couple of interesting digressions during Batchelor's visit. He was always frugal. Fu Chia shared one story with me. Batchelor made his second visit to China with his wife, Wilma Batchelor (1918-1997). When Fu Chia chatted with them in the hotel, he saw that Wilma was darning Batchelor's socks. Batchelor, said, in an apparently serious tone, that Wilma was brought to Beijing to do just that.

One more digression about Batchelor: on 28 October 2018, Longbo Li, Fu Chia's wife, told me a story which is included here with her permission. She recalled that Batchelor had invited his Chinese friends to dinner in Peking in 1983 and he suggested they should finish the dishes until there was no food left. When all the guests said that they were already full, Batchelor finished the remains of all the dishes. Li was still moved by Batchelor's frugality almost 40 years later.

\section{Batchelor And the 30th Anniversary of the Institute of Mechanics in 1986}

In 1986, the Institute of Mechanics decided to commemorate its 30th anniversary in the form of an international symposium addressing the problem of the development of mechanics in the

107 E. Zauner, 'A review of Proceedings of the Second Asian Congress of Fluid Mechanics', Geophys. Astrophys. Fluid Dynam. 39, 338-339 (1987). 


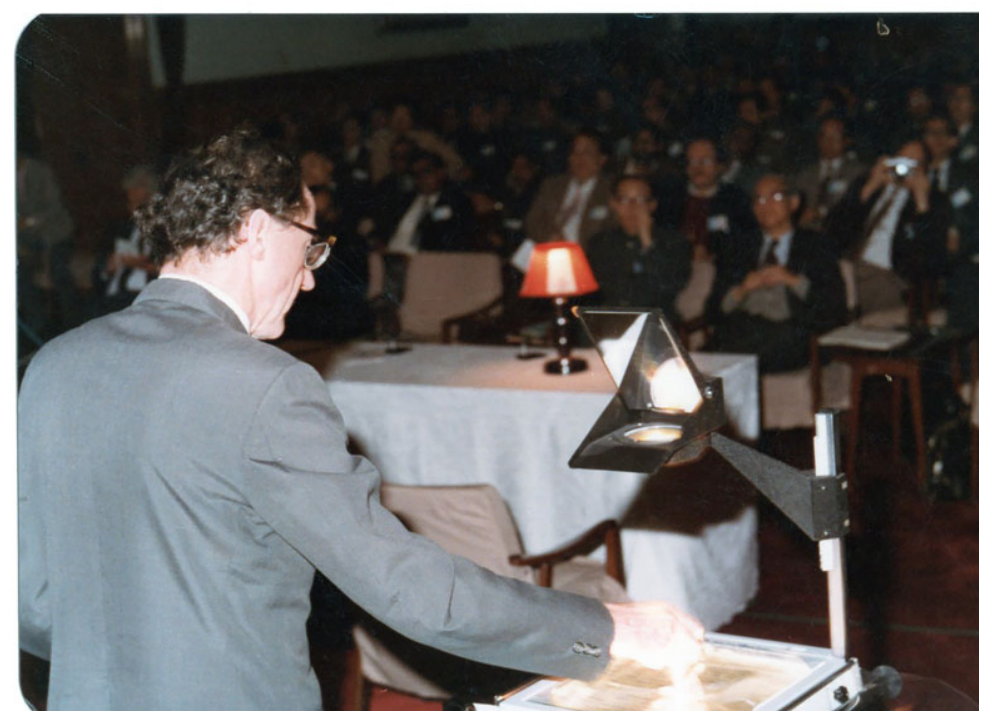

Figure 10. Batchelor presenting an invited talk at the Second Asian Congress of Fluid Mechanics, 25 October 1983, Peking. Batchelor is facing the audience, and Tung-Chi Lin and Chia-Chiao Lin are in the front row directly in front of Batchelor. (Online version in colour.)

next 15 years. It was planned that there would be a post-symposium trip to Chengde, ${ }^{108}$ which was once the summer resort of the Qing Dynasty. Batchelor was kindly invited as a distinguished guest to attend it. However, Batchelor was committed to making a visit to McGill University in Montreal, Canada, and thus did not make a third trip to China. In his reply letter to Yuan-Sheng Ma on 16 April 1986, Batchelor wrote, 'I am committed to making a visit to McGill University in Montreal, Canada, at exactly the time of the symposium. This is bad luck for me that I shall miss this opportunity of meeting my friends at the institute once more. ${ }^{109}$ Batchelor was officially invited by Wen-Rui Hu, the Chairman of the Department of Basic Research in Mechanics. Ching Sheng also sent his invitation letter to Batchelor. ${ }^{108}$

\section{BATCHELOR's INSPIRATIONAL INFLUENCE ON CHINESE FLUID DYNAMICISTS IN THE 1990s}

Batchelor ${ }^{110}$ obtained the scalar-variance spectrum in the viscous-convective range. Qian ${ }^{111}$ obtained closed equations of isotropic turbulence by the method of non-equilibrium statistical mechanics and a perturbation-variation approach. Qian ${ }^{112}$ applied his equations to the study

108 Letter, Ching Sheng to G. K. Batchelor, 2 April 1986, Batchelor Archive.

109 Letter from Batchelor to Yuan-Sheng Ma, 16 April 1986.

110 G. K. Batchelor, 'Small-scale variation of convected quantities like temperature in turbulent fluid. Part 1. General discussion and the case of small conductivity', J. Fluid Mech. 5, 113-133 (1959), at p. 126, equations 4.8 and 4.9.

111 J. Qian, 'Variational approach to the closure problem of turbulence theory', Phys. Fluids 26, 2098-2104 (1983), J. Qian, 'A passive scalar field convected by turbulence', Phys. Fluids 28, 1299-1304 (1985), J. Qian, 'Cascade model of turbulence', Phys. Fluids 31, 2865-2874 (1988).

112 J. Qian, 'The spectrum of a turbulent passive scalar in the viscous-convective range', J. Fluid Mech. 217, 203-212 (1990). 


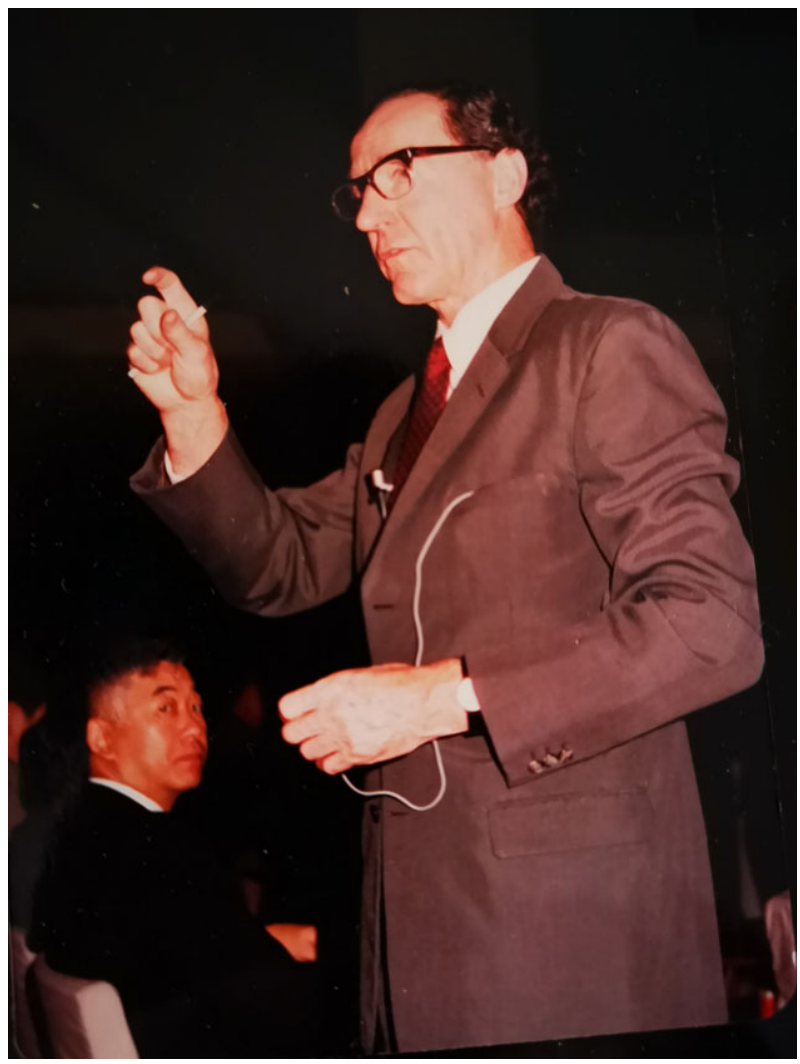

Figure 11. Batchelor answering a question from the audience after his invited talk on 25 October 1983, Peking. (Online version in colour.)

of the spectral dynamics of a turbulence passive scalar in the viscous-convective range and further confirmed Batchelor's $k^{-1}$ spectrum for the scalar for $\operatorname{Pr} \gg 1$ and $\operatorname{Pr} \ll 1$. Although the results are dimensionally inevitable, Qian's derivation is useful. Those results are fully plausible, but one must remember the results are based on a model.

As one digression, Lian-Ping Wang, who is currently Professor at the Southern University of Science and Technology, Shenzhen, China, recalls that he had the enormous pleasure of meeting Batchelor personally in the summer of 1992, when Batchelor chaired Wang's session at the Fourth European Turbulence Conference at the Delft University of Technology. Wang presented joint work with Martin Maxey on the interactions of microbubbles with vortical structures in homogeneous, isotropic turbulence, ${ }^{113}$ which is now regarded as the first study of this kind using direct numerical simulations. 


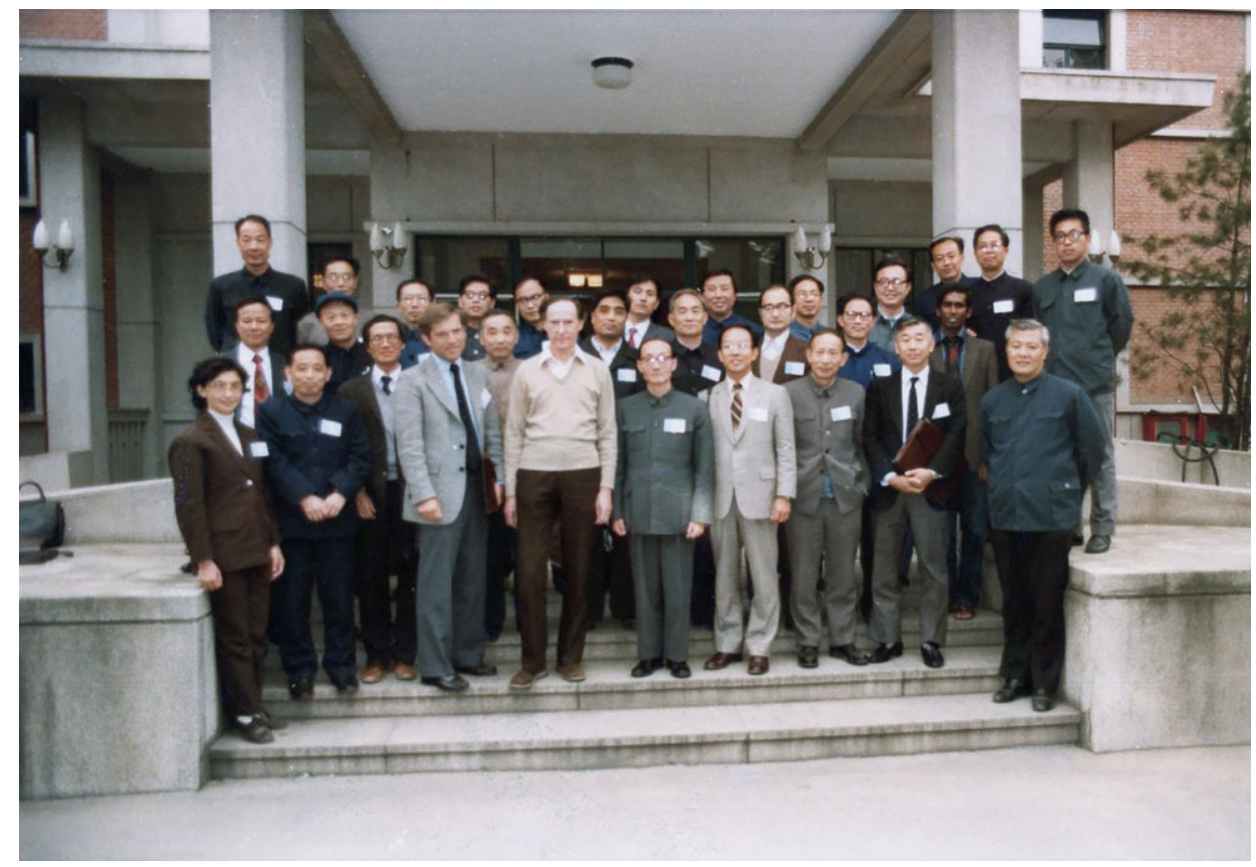

Figure 12. Batchelor photographed with other participants during a break in the Second Asian Congress of Fluid Mechanics on 28 October 1983, Peking. Those from the Institute of Mechanics include Fu Chia (third row, third from the right), Dieli Zhang (on the left of the first row), Tung-Chi Lin (dressed in the formal Sun Yat-sen suit, on Batchelor's left), and Liangru Pan (first row, third from the right). (Online version in colour.)

\section{BATCHELOR'S OTHER INSPIRATIONAL INFLUENCE ON CHINESE FLUID DYNAMICISTS}

Batchelor's inspirational influence on turbulence research has continued in mainland China. Since Batchelor ${ }^{32}$ disseminated the Kolmogorov theory to the Western turbulence community, a number of researchers have sought to improve on the Kolmogorov [K41] analysis $^{31,32}$ by matching solutions valid in the inertial subrange to those valid in the viscous dissipation range, i.e. considering finite Reynolds number effects on K41. Among them is one Chinese turbulence researcher, Jian Qian (1939-2018), who has published more than 27 single-authored international peer-reviewed papers dealing with aspects of the scaling properties of homogeneous, isotropic turbulence since $1983 .{ }^{114}$ An overview of 'Qian's method'115 appears in McComb. ${ }^{37}$ Notably, Qian investigated whether the secondorder exponent corresponds to normal Kolmogorov scaling or to anomalous scaling. Qian's method makes use of exact relationships incorporated with well-established data correlations available in the literature, so as to extract as much physics as possible from the available experimental results. Antonia and Burattini ${ }^{116}$ used an empirical model for the second-order velocity structure function in conjunction with the scale-by-scale energy

114 J. Z. Shi, 'Qian Jian', Physics Today (31 Dec 2018), https://physicstoday.scitation.org/do/10.1063/PT.6.4o.20181231a/full/.

115 J. Qian, 'Inertial range and the finite Reynolds number effect of turbulence', Physical Review E55, 337-342 (1997).

116 R. A. Antonia and P. Burattini. Approach to the 4/5 law in homogeneous isotropic turbulence, Journal of Fluid Mechanics, 550, 175-184 (2006). 
budget equation (in essence the Kármán-Howarth equation). The results were in qualitative agreement with Qian's predictions. More importantly, these predictions are fully consistent with the Reynolds number dependence exhibited by the bulk of the experimental and numerical data, e.g. Antonia et al. ${ }^{116,117}$ and Tang et al., ${ }^{118}$ not just for velocity derivative statistics but also for the second- and third-order velocity structure functions.

Homogeneous, isotropic turbulence, to which Batchelor had also contributed greatly, had been debated among some senior Chinese fluid dynamicists in the journal Scientia Sinica (Chinese edition) in the 2010s. The opposing view is exactly the same as that in Hans Wolfgang Liepmann's group in the 1950s, i.e. 'The argument appears to have that isotropic turbulence was almost never found in nature and was also hard to create in the laboratory. Turbulent shear flows, conversely, were certainly closer to real life and moreover fascinating to study. ${ }^{, 19}$ However, Huang and Chen ${ }^{120}$ argued that homogeneous, isotropic turbulence is a useful approach to our understanding of turbulence. By introducing a natural eigenvalue, $\operatorname{Ran}^{121}$ obtained an equation for decay of turbulence kinetic energy isotropic turbulence.

It might be interesting to consider whether Batchelor's influence was completely beneficial. His early emphasis on homogeneous turbulence led people into what became a rather sterile topic. He did move on. ${ }^{122}$ As $\mathrm{McComb}^{37}$ wrote in his book's Preface, 'homogeneous, isotropic turbulence, it even has its own three-letter acronym (HIT): a sure sign of success!'

\section{The 50th Anniversary of the G. K. Batchelor Laboratory in 2014}

Batchelor set up DAMTP against considerable opposition, ${ }^{123}$ especially his plan for it to include an experimental laboratory. ${ }^{124}$ DAMTP was initially housed in the Phoenix Wing at the top of the Cavendish Laboratory in Free School Lane. ${ }^{125}$ Its formation was partly driven by the aim to give Dirac a home that was not in Physics owing to internal tensions and interpersonal conflicts within that department. Fluids, however, was also a big motivation. ${ }^{124}$ In 1964, an old building of the Cambridge University Press was converted for use by the newly established DAMTP. In the basement of the building, there was space for a small laboratory suitable for experimental work on fluid mechanics. ${ }^{95}$ Thus, the Fluid Dynamics Laboratory was established. Experimental work in the laboratory has been under the general direction of Thomas Brooke Benjamin (1929-1995, FRS 1966), John Stewart Turner (FRS 1982), Paul Linden and currently Stuart Bruce Dalziel.

After the fluid dynamicists had all moved to the Centre for Mathematical Sciences in December 2002, the old Fluid Dynamics Laboratory was named the G. K. Batchelor Laboratory. This was because Batchelor believed that theoretical fluid mechanics only

117 R. A. Antonia, S. L. Tang, L. Djenidi and L. Danaila, 'Boundedness of the velocity derivative skewness in various turbulent flows', J. Fluid Mech. 781, 727-744 (2015).

118 S. L. Tang, R. A. Antonia, L. Djenidi, L. Danaila and Y. Zhou, 'Reappraisal of the velocity derivative flatness factor in various turbulent flows', J. Fluid Mech. 847, 244-265 (2018).

119 R. Narasimha, A. Roshko and M. Gharib, op. cit. (note 5).

120 Y. N. Huang and Y. S. Chen, 'On the Discussion about "What is the essence of the so-called centuries-old difficult problem in classical physics, the "problem of turbulence"?"” (in Chinese), Sci. Sin. Phys. Mechs Astron. 42, $445-447$ (2012).

121 Z. Ran, Decay and eigenvalue problems in isotropic turbulence, arXiv 1606.06373 (2016).

122 Chris Garrett, personal communication, 14 June 2019.

123 Herbert Huppert, personal communication, 4 June 2019.

124 Stuart Dalziel, personal communication, 7 June 2019.

125 G. F. R. Ellis and R. Penrose, 'Dennis William Sciama', Biogr. Mems Fell. R. Soc. Lond. 56, 401-422 (2010), p. 414. 


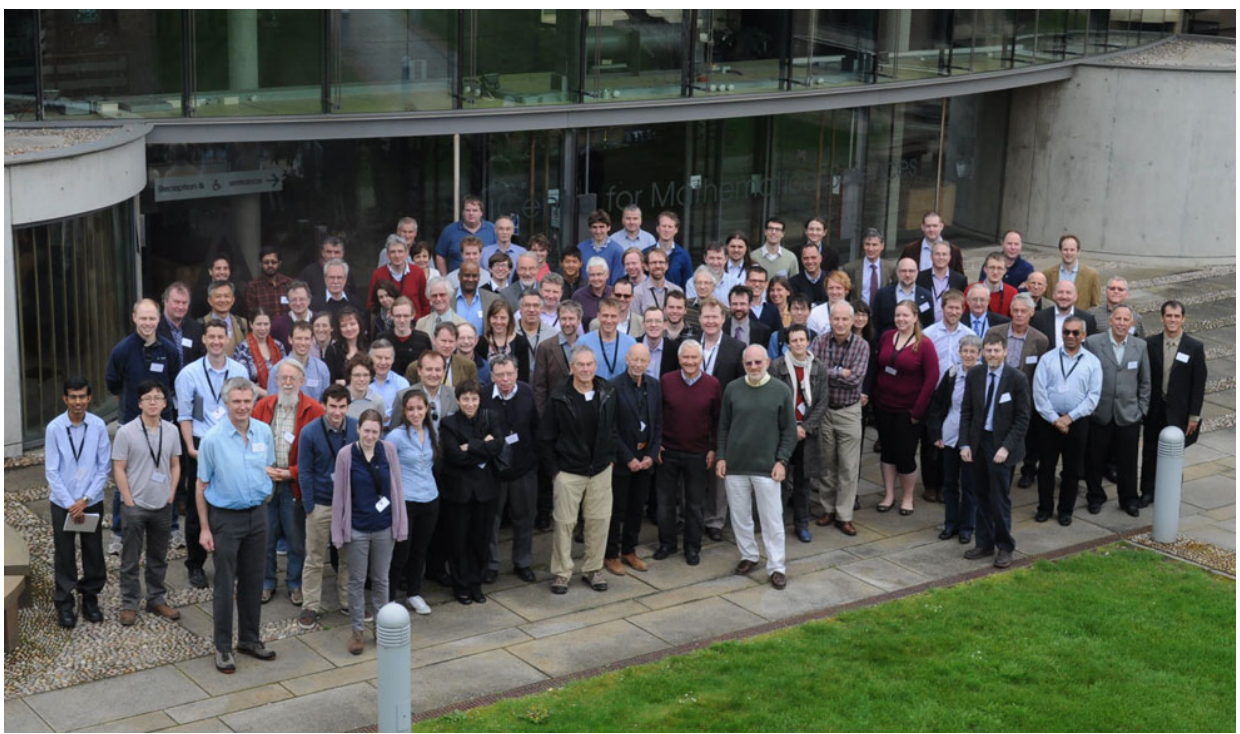

Figure 13. Group photo taken at the 50th Anniversary of the G. K. Batchelor Laboratory in April 2014, Cambridge. Reproduced with permission. Copyright (C) The G. K. Batchelor Laboratory. (Online version in colour.)

made sense if it was aimed at understanding real phenomena, and therefore insisted on a laboratory when DAMTP first got its own building in $1964 .{ }^{126}$ For the new laboratory 'Fluid Dynamics' was intentionally dropped from the name, both to limit the length of the name, but more importantly to make it more inclusive and allow other areas to feel 'at home'. Examples of these areas include granular flows and biological physics. The suggestion for the name change initially came from Keith Moffatt. ${ }^{124}$ The present author was also fortunate indeed to have had a three-month visit to the G. K. Batchelor Laboratory in 2012 to carry out laboratory experiments on turbulence and mixing in a mean-shear free stably stratified two-layer fluid ${ }^{127}$ and then on the turbulent structures in a homogeneous fluid and a mean-shear free stably stratified two-layer fluid again in Michaelmas Term of 2019.

A symposium celebrating the 50th Anniversary of the G. K. Batchelor Laboratory was held at DAMPT in April 2014 (figure 13), which I attended along with another Chinese fluid dynamicist, Jian Deng, who was visiting DAMTP.

126 Tim Pedley, personal communication, 26 October 2018.

127 J. Z. Shi and S. Zhang, 'Laboratory experiment on turbulent mixing and fractal dimension of a density interface in a stably stratified fluid', Procedia Engng 126 (C), 103-107 (2015), J. Z. Shi and S. Zhang, 'Corrigendum to 'Laboratory experiment on turbulent mixing and fractal dimension of a density interface in a stably stratified fluid' Procedia Engng 126 103-107 (2015)]', Procedia Engng 126, 745-746 (2015), J. Z. Shi and S. Zhang, 'Turbulent mixing across a shear free density interface in a stably stratified fluid', in Proceedings of the Institute of Mathematics and its Applications (IMA) Conference on Turbulence, Waves and Mixing (in honour of Lord Julian Hunt's 75th Birthday), King's College, Cambridge (eds S. G. Sajjadi and H. J. S. Fernando), pp. 33-36 (2016). 


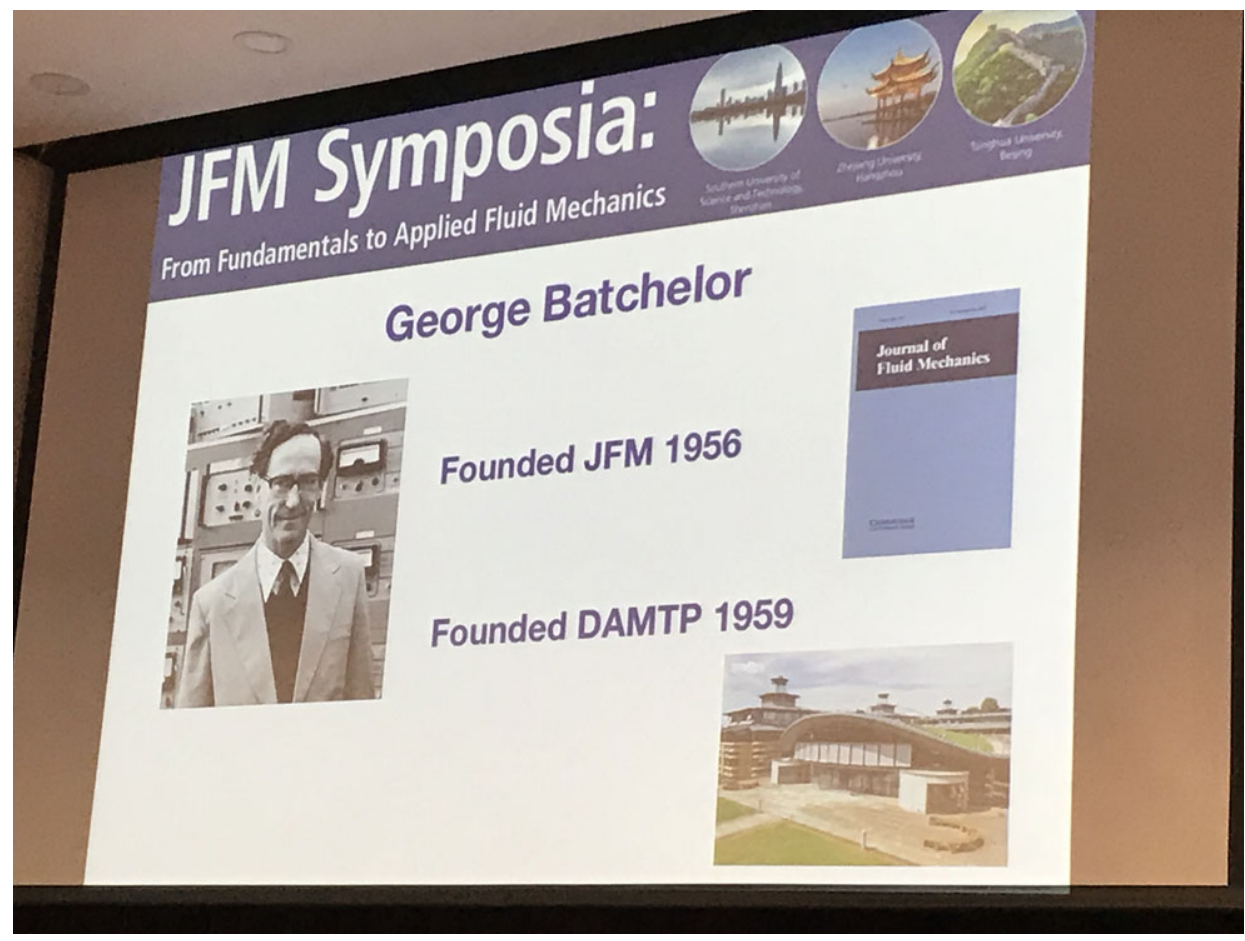

Figure 14. One of the slides prepared by Grae Worster presented by Charles Meneveau at the JFM symposium in Hangzhou, Zhejiang Province, China, on 7 November 2018. (Online version in colour.)

\section{JFM SYMPOSIA IN CHINA IN 2018}

In the 1950s Batchelor saw the need for a new journal in fluid mechanics. The first part of volume 1 of the Journal of Fluid Mechanics (JFM) appeared in May 1956. In November 2018, the JFM Symposium From Fundamentals to Applied Fluid Mechanics was held in Shenzhen, Hangzhou and Beijing, China. As shown in figure 14, in one of the slides prepared by Grae Worster and presented by Charles Meneveau at the symposium in Hangzhou, George Batchelor was acknowledged to have founded JFM in 1956 and the Department of Applied Mathematics and Theoretical Physics (DAMPT) in 1959. Paul Linden and Colm-Cille Patrick Caulfield, from DAMTP, Detlef Lohse and Charles Meneveau were present at the symposium. Batchelor would have been pleased to know about these events in China since he had tried to establish a tie with the Chinese fluid mechanics community ever since 1980 .

Increasing numbers of Chinese scientists and engineers are currently working in the field of fluid mechanics. More and more scientific research papers by Chinese fluid dynamicists have been published in JFM. There are several projects related to fluid mechanics, especially turbulence, funded by the National Natural Science Foundation of China, e.g. the project entitled Physical Mechanisms of the Formation, Evolution and Interaction of Turbulence Structures (no. 91752000), for the period 2018-2025. 


\section{DisCUSSION}

From the perspective of a historian, it is not sufficient to say merely that Batchelor was an important scientist and to provide a narrative biography. It is also essential to attempt to advance an original historical argument situated in the historiography of the field, particularly in the past work of other historians of science in China and concentrating on turbulence studies.

This article as a whole could be thought of as such an argument. For instance, the present author suggests at the start of the main text that Batchelor's legacy is an important star in the fluid-mechanical firmament, based on the evidence in all the citations given. ${ }^{128}$ However, it would be better to cite those other historians within the main narrative wherever they bear on a point then being made. Of course it is difficult to cover all conceivable historical points.

The parallel case of Batchelor's encouragement of links with Poland suggests that he was pursuing a more general or systematic strategy of international West-East engagement than the China case alone. Batchelor had sympathy for an 'Iron Curtain' country such as Poland and a 'Bamboo Curtain' country such as China.

The quality and range of historiography of twentieth-century fluid dynamics is patchy. Some of the useful contributions are as follows. A history of fluid dynamics of Russian scientific schools in the twentieth century is given by Betyaev. ${ }^{129}$ Lumley and Yaglom ${ }^{130}$ gave a survey of some very personal nominations for high points of the last hundred years in turbulence studies. Davidson et al. ${ }^{131}$ edited the book entitled $A$ voyage through turbulence containing biographies of twelve of its great personalities, starting with Osborne Reynolds and his pioneering ideas of the 1880s, which have provided absorbing reading for every scientist, mathematician and engineer interested in the history and culture of turbulence. Barenblatt and Chorin ${ }^{132}$ presented a personal view of the problem of turbulence as a whole. They concluded that turbulence at very large Reynolds numbers (often called developed turbulence) is widely considered to be one of the happier provinces of the turbulence realm, as it is thought that two of its basic results are well established, and have a chance to enter, largely untouched, into a future complete theory of turbulence. These are (i) the von Kármán-Prandtl universal logarithmic law in the wall region of wall-bounded turbulent shear flow, and (ii) the Kolmogorov-Obukhov scaling laws for the local structure of developed turbulent flow. ${ }^{132}$

What specifically did Batchelor contribute? As presented earlier, Batchelor discovered the Russian work and disseminated the Kolmogorov-Obukhov scaling laws to the Western world. What did Chinese fluid dynamicists contribute? As also presented earlier, they improved the Kolmogorov-Obukhov scaling laws, notably with the Finite Reynolds Number Effect work done by Qian. ${ }^{115}$ Batchelor's major contributions span the period 1946-1992 and are for the most part concerned with the Kolmogorov theory of the small scales of motion, the decay of homogeneous turbulence, turbulent diffusion of a passive scalar field,

128 J. C. R. Hunt; H. E. Huppert; T. J. Pedley; J. Rallison; G. I. Barenblatt; L. van Wijngaarden; H. K. Moffatt; H. K. Moffatt; H K. Moffatt; H. K. Moffatt; H. K. Moffatt; J. H. Arakeri, op. cit. (note 2).

129 S. K. Betyaev, 'On the history of fluid dynamics: Russian scientific schools in the $20^{\text {th }}$ century', Physics Uspekhi $46,405-432$ (2003).

130 J. L. Lumley and A. M. Yaglom, 'A century of turbulence', Flow Turb. Combust. 66, 241-286 (2011)

131 P. A. Davidson, Y. Kaneda, K. Moffatt and K. R. Sreenivasan (eds), A voyage through turbulence (Cambridge University Press, 2011).

132 G. I. Barenblatt and A. J. Chorin, 'Turbulence: an old challenge and new perspectives', Meccanica 33, 445-468 (1998). 
magnetohydrodynamic turbulence, rapid distortion theory, two-dimensional turbulence, and buoyancy-driven turbulence. ${ }^{133}$ Eckert $^{134}$ reviewed the surge of turbulence research in the first half of the twentieth century with the focus on the institutional environment that provided an umbrella for the activities in the field of turbulence. Eckert ${ }^{134}$ also highlighted Batchelor's important role in the foundation of a new journal, the Journal of Fluid Mechanics, where recent research results on turbulence were published.

Was Batchelor's influence on Chinese fluid dynamics (turbulence) entirely beneficial or not? Did his influence lead to over-emphasis on a topic - homogeneous, isotropic turbulence-that Batchelor himself had moved away from? I will try to address these questions.

The following lines are from Batchelor's letter to $\mathrm{Tu}(\mathrm{Du})$-Cheng Yeh (Ye) dated 12 March 1979: 'I myself am not engaged in research on turbulence at the moment, but I of course retain a general interest in the subject and some of my colleagues here are actively involved in research on turbulent dispersion and diffusion in the atmosphere and ocean. $^{135}$

Batchelor did conclude after the Marseilles symposium of 1961 that the study of turbulence had reached an impasse. However, it is clear from Batchelor's letter to Yeh that he retained a general interest in turbulence studies in the 1970s and 1980s.

Even after the Marseilles symposium, studies of turbulence have continued all over the world. Notably, a few books have been published, e.g. Homogeneous, isotropic turbulence $^{37}$ and Homogeneous turbulence dynamics. ${ }^{136}$ Those two books have similar titles to that of Batchelor. ${ }^{11}$

In parallel with this global trend, Chinese fluid dynamicists have continued to work on turbulence. If Batchelor deliberately or otherwise tried to 'gently steer' Chinese scientists away from homogeneous, isotropic turbulence studies, as some have wondered, then there is no evidence of it. In keeping with this view, the English turbulence expert Julian Hunt states that 'Batchelor did not discourage others to continue their studies of turbulence.'137

It would seem highly improbable that Batchelor would have discouraged Chinese fluid dynamicists from pursuing research in small-scale turbulence, given the significant contributions that he made in this domain. A case can be made instead that Batchelor's papers and book ${ }^{11}$ would have inspired Chinese researchers to study further aspects of homogeneous, isotropic turbulence in much the same way as he inspired non-Chinese researchers.

It can be argued that Batchelor's influence on Chinese fluid dynamics (turbulence) has been beneficial in one way or another. Chinese fluid dynamicists have not over-emphasized homogeneous, isotropic turbulence. Certainly, Chinese fluid dynamicists have made significant contributions to turbulence studies. Notably, Qian ${ }^{115}$ identified the importance of the Finite Reynolds Number Effect and steered all of us along the right path ${ }^{138}$ to an improved understanding of fluid dynamics and solutions to its problems.

The record of interactions shows that many scientists and mathematicians encouraged or developed international links. As previously discussed, links between the People's

133 H. K. Moffatt, op. cit. (note 2).

134 M. Eckert, op. cit. (note 5).

135 Batchelor's letter to Yeh, dated 12 March 1979, Batchelor Archive.

136 P. Sagaut and C. Cambon, Homogeneous turbulence dynamics (Springer, Berlin, 2018).

137 Julian C. R. Hunt, personal communication, Common Room of Pavilion H, DAMTP, 31 October 2019.

138 Robert Antonia, personal communication, 16 October 2019. 
Republic of China and the UK were rebuilt in the 1970s. ${ }^{14}$ Batchelor bravely interacted with Chinese fluid dynamicists. These interactions truly mattered for the development of fluid mechanics in both the UK and China. There is further evidence to substantiate this statement.

For example, Tu (Du)-Cheng Yeh (Ye), Vice-President of the Chinese Academy of Sciences, wrote to Batchelor: 'We have never met each other before, but I have known from your works. Your works have many influences in our country. ${ }^{139}$

As another fine example, in his letter to Yeh (Ye) dated 18 December 1981, Batchelor wrote $^{140}$

Dear Professor Yeh (Ye),

We spoke today about the work which Wen Ching-sung has done while he has been in Cambridge. His stay in Cambridge for the past two years represents a considerable investment by the Chinese Academy of Sciences and by the Department in which he has worked, we would all like to see that investment yield scientific dividends.... Wen has played an active part in this work, and it could not have been done without him. During his stay here he has learnt a good deal of basic fluid mechanics, he has learned how to use a large computer efficiently and to solve mathematical problems numerically, and he has been introduced to the concepts and methods of colloid and aerosol science and their application to problems of cloud physics. I think it would be in the interests of the Chinese Academy of Science(s) to enable Wen to continue research in aerosol dynamics and cloud physics. In that way China would get maximum benefit from the experience and training which he has received here. And I personally would hope to continue to collaborate with him on problems in this field, which is becoming important in considerations of atmospheric pollution.

It can be seen from Yeh's and Batchelor's letters that Batchelor's interaction with this Chinese fluid dynamicist was beneficial to both sides. But this was not the only instance.

As presented earlier, there is a revealing set of responses by Batchelor in which Chinese scientists asked him important questions about the organization of science, the division between pure and applied mathematics, his views about Russian science and mathematics, and lessons to be learned. Batchelor's responses to the questions on the organization of science reveal a leading figure addressing seriously and at reasonable length some of the crucial developments of the political and disciplinary organization of science, which should be valuable to a broad readership in the history of modern science. For example, Batchelor expressed his view about how fluid mechanics research could be valuable in industry. It should be pointed out that Batchelor's ideas about policies of research application partly resulted from his working in aeronautical research during World War II.

What might we learn from Batchelor's answers? The following three selected examples will show the reactions of some current British scientists to Batchelor's responses and what they might learn from his answers:

Example I. Stuart B. Dalziel, Director of the G. K. Batchelor Laboratory, DAMTP, Cambridge, commented on Batchelor's responses to questions raised by Chinese scientists: 'This is very interesting. It is wonderful that those tapes were found and transcribed!' 124

Example II. W. David McComb, an expert in homogeneous, isotropic turbulence, Emeritus Professor of Physics at the University of Edinburgh, also commented on Batchelor's

139 Letter to Batchelor from Du-cheng Yeh, dated 6 February, 1982, Batchelor Archive.

140 Letter from Batchelor to Yeh, dated 18 December 1981, Batchelor Archive. 
responses to questions raised by Chinese scientists: 'If I were to pick out one thing, it would be the transcripts of the tape recordings of his discussion with his Chinese visitors. I thought his views on how research should be supported and conducted were interesting. ${ }^{141}$

Example III. John Raymond Willis (FRS 1992), Emeritus Professor of Theoretical Solid Mechanics, University of Cambridge, was also impressed by Batchelor's responses to questions raised by Chinese scientists: 'What did strike a chord with me were George's answers to the questions: his attitude towards both science itself and its administration is close to what mine is now-and obviously out of touch with the way the powers that be, and the funding agencies, expect it to be today! 142

Those three examples are representative of a range of ages, academic careers and research fields. As Director of the G. K. Batchelor Laboratory, Dalziel felt that Batchelor's foundation of the laboratory was very important to fluid mechanics. McComb especially felt that we could still learn from Batchelor's views on how research should be supported and conducted. Willis happily found that Batchelor's attitude towards both science itself and its administration is close to what his is now, and strongly felt that we could still learn from Batchelor regarding these two aspects today.

How did Batchelor's vision of applied mathematics in fluid dynamics specifically affect Chinese fluid dynamicists? How did their approaches influence Batchelor? It was a mutual process. This argument has already been included above. Batchelor's two major academic fields were: homogeneous, isotropic turbulence, and microhydrodynamics. One may wonder whether Batchelor's influence was completely beneficial or not. Perhaps his early emphasis on homogeneous, isotropic turbulence led fluid dynamicists into what became a rather sterile topic. Batchelor's vision of homogeneous, isotropic turbulence also inspired and assisted Chinese turbulence studies. As Batchelor did, Chinese fluid dynamicists moved on to make contributions to other areas. For example, two Chinese fluid dynamicists, Ching Shen and Ching Song Wen, contributed much to the field of microhydrodynamics. The fact that Batchelor's talks during his two visits to China were not about turbulence should indicate that Chinese scientists were not continually pushed by Batchelor, intentionally or unintentionally, into studying only homogeneous, isotropic turbulence.

Both English and Chinese versions of Batchelor's An introduction to fluid mechanics, together with his famous monograph The theory of homogeneous turbulence, have had great inspirational influence on generations of fluid dynamicists in China. I have demonstrated the range of these influences both through Batchelor's publications and through his two visits to China. It is evident that Batchelor's views on how research should be supported and conducted are still of interest to Chinese fluid dynamicists.

\section{CONCLUDING REMARKS}

Without George Batchelor, modern fluid mechanics would not be the discipline it is today. ${ }^{143}$

141 W. David McComb, personal communication, 16 June 2019.

142 John R. Willis, personal communication, 26 October 2019.

143 J. C. R. Hunt, op. cit. (note 2). 
Batchelor's insistence on starting with physical phenomena comes across strongly. This would likely have been shared by the Chinese mathematicians. ${ }^{144}$ Batchelor came to know China well, and he in turn was known there and widely respected. The articles about Batchelor by $\mathrm{Wen}^{145}$ were assembled into his slim volume. ${ }^{87}$ It was $\mathrm{Wen}^{87,145}$ who introduced Batchelor and DAMTP, Cambridge, to the Chinese fluid mechanics community. Ran and $\mathrm{Pan}^{146}$ brought together a few historical stories about the fluid mechanics master George Batchelor.

In the 1980s, Batchelor's work with China was not purely a personal relationship; instead it very much represented both a larger political and scientific relationship between the two countries as delineated by Agar. ${ }^{14}$ Batchelor's work with China does provide a specific example of the renewal of China-UK scientific relations in the 1970s.

Batchelor left us a legacy. The success of DAMTP has been mainly due to Batchelor, who was able to attract many talented fluid dynamicists from all over the world. Can the spirit of the department established by Batchelor be copied by or transferred to other countries such as China? Yes, with care and attention. ${ }^{147}$ The tie between the Chinese fluid mechanics community and DAMTP should be maintained and further strengthened since it is important to both sides.

It is clear that the changing political context does matter. After the broader development of fluid dynamics and the changing political ties between the two countries, it is possible for us to list some precise contributions of Batchelor to Chinese fluid mechanics: (1) DAMTP, which he had founded, has attracted many Chinese fluid dynamicists to visit and do their research there; (2) the IUTAM and the EUROMECH conferences, with which Batchelor was involved, have provided Chinese fluid dynamicists with important forums for their scientific research results; (3) the Journal of Fluid Mechanics, which he founded, has provided Chinese fluid dynamicists with a leading fluid mechanics journal in which to publish their best scientific results; (4) the monograph The theory of homogeneous turbulence $^{11}$ continues to inspire Chinese turbulence researchers; (5) the textbook $A n$ introduction to fluid dynamics ${ }^{53}$ in English and its Chinese translation continues to inspire Chinese postgraduate students and fluid dynamicists.

According to Moffatt, Batchelor's first meeting with Chinese scientists was in 1978, at the meeting of the General Assembly of IUTAM, held on that occasion at University College London. China had applied to become an 'Adhering Organisation' of IUTAM and was represented by Zhemin Zheng, Director of the Academy's Institute of Mechanics, and Ren Wang, Chairman of the Department of Mechanics at Peking University; their presence at this meeting, just two years after the death of Mao Zedong and the end of the Cultural Revolution, made a dramatic impression; China was duly admitted to IUTAM at the next opportunity, the 1980 congress of IUTAM in Toronto.

Batchelor also helped develop contacts with the Chinese fluid mechanics community through IUTAM, but China did not contribute much to IUTAM until they put in bids to host ICTAM, which were eventually successful and led to the 2012 ICTAM in Peking. The first East-West joint international meeting on fluid mechanics under the auspices of the United Nations Organization, which took place in Beijing in 1992, was led by Sir

144 Jon Agar, personal communication, 9 August 2019.

145 C. S. Wen; C. S. Wen; C. S. Wen, op. cit. (note 86).

146 Z. Ran and S. Q. Pan, 'A few historical stories about the Fluid Mechanics Master Batchelor' (in Chinese), Mechs Engng 33, 82-83 (2011).

147 Herbert Huppert, personal communication, 4 June 2019. 
(Michael) James Lighthill (1924-1998, FRS 1953). Hunt was also present. The first IUTAM symposium held in the People's Republic of China was in 1992, in Beijing, and there have been many since-but all in solid mechanics not fluids. A single exception may be one with the title 'The dynamics of extreme events influenced by climate change', held in Lanzhou in 2013. This symposium was co-chaired by Paul Linden and Xiaojing Zheng (from Lanzhou University), and Keith Moffatt as the IUTAM representative and member of the scientific committee provided warm support from the proposal to the preparation of the symposium. Forty scholars from 10 countries (China, UK, France, German, Russia, South Africa, Ireland, Japan, Singapore, Sri Lanka) presented and discussed experiments, theoretical and numerical modelling of extreme events introduced by climate change from the perspective of fluid mechanics. Xiaojing Zheng presented a talk entitled 'Field observations on the turbulent features of the near-surface flow fields and dust transport during dust storms'. Frederic Dias, the former Secretary General of IUTAM, presented and gave highly complimentary remarks to the symposium. The link between DAMTP and Chinese fluid dynamicists is continuing, and another IUTAM symposium entitled 'Turbulent structure and particles-turbulence interaction' will be held at Lanzhou University, China, in 2020 with Keith Moffatt as the IUTAM representative again.

\section{ACKNOWLEDGEMENTS}

The writing up of this article was strongly motivated by my talk entitled 'The G. K. Batchelor Fluid Dynamics Laboratory, University of Cambridge, UK: a personal perspective', presented at the State Key Laboratory for Turbulence and Complex Systems, Peking University, China, on Friday 21 September 2018 during my short visit there. It was also partially motivated by Paul Linden's one-week visit to the State Key Laboratory for Turbulence and Complex Systems, Peking University, China, in October 2018. Cunbiao Lee, the Executive Deputy Director of State Key Laboratory for Turbulence and Complex Systems, is thanked for having kindly hosted both of us at Peking University. Fu Chia, who had very much enjoyed his trip down memory lane from the copy of my talk at Peking University sent to him, kindly provided me with those old photos shown in figures 3-12. Grae Worster kindly permitted use the image of his slide shown in figure 14. Fu Chia luckily found the tape recording related to Batchelor's meeting with a Chinese delegation at Cambridge. Julian Hunt, Keith Moffatt, Paul Linden and Timothy John Pedley have kindly encouraged me to write up this article. Jonathan Smith, Archivist and Modern Manuscript Cataloguer of Trinity College Library, University of Cambridge, is thanked for providing me with the list of Batchelor's archive and some material presented in this article. William Perrie is thanked for finding me Synge and Lin (1943). Pedley went to the Royal Society to find out who the Executive Secretary of the Royal Society was in 1980. I was a recipient of the Sino-British Friendship Scholarship Scheme, proposed by Sir Yue-Kong Pao (1918-1991), in 1987, and am happy to contribute to the Sino-British Friendship through this article. This article is dedicated to Lan-Xiang Zhang (1937-2017). Various early drafts of this article were carefully reviewed and corrected by Stuart Dalziel, Les Hamilton and David Pritchard. In particular, Herbert E. Huppert carefully reviewed and corrected two draft versions. David Pritchard kindly listened to the tape and made corrections to the early version of the text of the transcript of Batchelor's discussion with the Chinese delegation in 1981. Keith Moffatt kindly deposited a copy of the SONY disk containing tapes in the 
Batchelor Archive at the Wren Library, Trinity College, Cambridge. The following people kindly read and commented on the various drafts: Jonathan Agar, Robert Antonia, Helmut Baumert, Christopher Garrett, Ruifeng Hu, Julian Hunt, Fu Chia, Dongqiang Lu, Ivan Marusic, W. David McComb, Charles Meneveau, Keith Moffatt, Anna Marie Roos, Lianping Wang, Leen van Wijngaarden, Xiaojing Zheng, Song-Ping Zhu and John Willis. The revision was completed when the author was a Visiting Fellow of Wolfson College, Cambridge, during Michaelmas Term 2019. The China Scholarship Council is thanked for having provided the present author with a Senior Research Fellowship via the State Scholarship Fund (File no. 201906235002). Krzysztof Mizerski is thanked for spotting the misspelling of Wladyslaw (Wladek) Fiszdon. Robert Antonia is thanked for his suggestion regarding whether Batchelor's influence is really beneficial or not. Four anonymous reviewers are thanked for their critical comments which have improved the quality of this article. Xiao-Hong Huang is thanked for her patience. Les Hamilton carefully reviewed and corrected the final revision. Michael Edgeworth McIntyre is thanked for his constructive comments on the final version. Sarah Bendall is thanked for her clarification of the building's name and site shown in figure 6. 